\title{
Assessing treatments used to reduce rumination and/or worry: A systematic review.
}

Dawn Querstret

School of Psychology, University of Surrey

d.querstret@surrey.ac.uk

\author{
Mark Cropley \\ School of Psychology, University of Surrey \\ mark.cropley@surrey.ac.uk
}

\begin{abstract}
$\underline{\text { Abstract }}$
Perseverative cognitions such as rumination and worry are key components of mental illnesses such as depression and anxiety. Given the frequent comorbidity of conditions in which rumination and worry are present, it is possible that they are underpinned by the same cognitive process. Furthermore, rumination and worry appear to be part of a causal chain that can lead to long-term health consequences, including cardiovascular disease and other chronic conditions. It is important therefore to understand what interventions may be useful in reducing their incidence. This systematic review aimed to assess treatments used to reduce worry and/or rumination. As we were interested in understanding the current treatment landscape, we limited our search from 2002 to 2012. Nineteen studies were included in the review and were assessed for methodological quality and treatment integrity. Results suggested that mindfulness-based and cognitive behavioural interventions may be effective in the reduction of both rumination and worry; with both Internet-delivered and face-to-face delivered formats useful. More broadly, it appears that treatments in which participants are encouraged to change their thinking style, or to disengage from emotional response to rumination and/or worry (e.g., through mindful techniques), could be helpful. Implications for treatment and avenues for future research are discussed.
\end{abstract}

Keywords: Rumination, Worry, Perseverative cognition, Systematic review

\section{Introduction}

The aim of this systematic review was to assess treatments used to reduce rumination and/or worry. 


\section{The definition of rumination and worry}

There are many definitions of worry and rumination. The most often used definition of worry suggests that it constitutes a chain of thoughts and images that are affectively negative and relatively uncontrollable (Borkovec, Robinson, Pruzinsky, \& DePree, 1983; Borkovec, Ray, \& Stober, 1998). Descriptively, worry is dominated by negatively valenced thought activity, most often about negative events we are afraid will occur in the future (Borkovec et al., 1998). However, although worry is often associated with negative effects, it may also have some value. For example, day-to-day worries may function to motivate the individual to deal with a perceived threat that is causing worry (Davey, 1993); and many of these daily worries appear to be related to problem-solving. For example, in a study by Szabo \& Lovibond (2002) students were asked to self-monitor and record worry-related thoughts when they worried at least a little. These reported thoughts were then categorised by independent raters and over half of the thoughts involved problem solving; e.g., worrying about how to resolve a dispute with a friend, break up with a respective other, or make a plan for the coming day/s. The other half were more stereotypically worry-related thoughts such as anticipating bad outcomes or self-blame for events or situations that had not turned out as planned. Therefore, worry could be a constructive process (if the process results in a solution to a perceived problem) or a non-constructive process (if not focussed on solving a problem; or if an appropriate solution cannot be arrived at).

When it comes to rumination, there are many different definitions, all of which share the common experience of repetitive, intrusive, negative cognitions (see Papageorgiou \& Siegle, 2003). Some of these definitions are narrow. For example, Nolen-Hoeksema's (1991) wellknown definition of depressive rumination suggests that the focus of rumination is on one's own depressive symptoms. Other definitions are very broad. For example, Martin \& Tesser (1996), in their self-regulation model of ruminative thought, define rumination in the context of thinking about one's own goals, suggesting that this thinking may occur in the absence of immediate environmental cues. According to Martin \& Tesser (1996) there are three mechanisms by which ruminative thinking can be stopped: distraction, disengagement from the goal, and goal attainment.

\section{The link between rumination and worry}

Recurrent negative thinking or thought is a primary component of mood-related emotional disorders. Research regarding rumination and/or worry has been dominated by 
clinical/health psychology, with rumination and worry thought to be implicated in the aetiology of a number of psychological disorders, e.g., depression and anxiety (Lyubomirsky, Caldwall, \& Nolen-Hoeksema, 1998; Mellings \& Alden, 2000), and associated with increased physical symptom reporting (Hazlett \& Haynes, 1992), intrusive off-task thoughts (Sarason, Pierce, \& Sarason, 1996), negative self-evaluations, diminished feelings of control and feelings of helplessness (Lyubomirsky, Kasri, \& Zehm, 2003). Furthermore, laboratory studies have shown prolonged physiological arousal and delayed recovery in individuals who ruminate or who are asked to recall stressful events (Glynn, Christenfeld, \& Gerin, 2002; Ironson et al., 1992; Lampert, Jain, Burg, Batsford, \& McPherson, 2000; Roger \& Jamieson, 1988).

Barlow \& DiNardo (1991) proposed that worry is "fundamentally a presenting characteristic of all anxiety disorders with the possible exception of simple phobia" (p. 115); and worry also occurs frequently in major depression (Chelminski \& Zimmerman, 2003). Although studies tend to examine worry in relation to anxiety and rumination in relation to depression, a few studies have looked at the effects of both of these forms of repetitive thinking. For example, Segerstrom, Tsao, Alden, \& Craske (2000) examined the effects of these processes concurrently and found that repetitive thought of either kind was related to both anxious and depressed symptoms. More recently, McLaughlin, Borkovec \& Sibrava (2007) induced worry and rumination in a student sample to assess whether or not they affected mood in the same, or different, ways. They found that worry and rumination were both associated with increases in anxiety, depression and negative affect, and with decreases in positive affect. Interestingly, their analysis also indicated that shifting from worry to rumination resulted in decreased anxiety and increased depression; and shifting from rumination to worry created an opposing pattern.

Therefore, when the two forms of thinking occur sequentially, it appears worry is associated with predominantly anxious affect, and rumination is associated with predominantly depressive affect. As such, both processes appear to lead to the generation of negative mood states; with the different outcomes reflective of the focus or content of rumination or worry respectively. These findings are further supported by the results of prior studies conducted separately on worry and rumination. For example, Segerstrom, Stanton, Alden, \& Shortridge (2003) found that negative affectivity is generated by negative thinking of any type; Chelminski \& Zimmerman (2003) found that worry occurs in depression; and Nolen-Hoeksema (2000) found that rumination predicts the onset of anxiety. These findings suggest a shared component to these 
forms of repetitive thinking and a considerable research base supports this showing that anxiety and depression are frequently comorbid (Brown \& Barlow, 1992; Brown, Campbell, Lehman, Grisham, \& Mancill, 2001; Kessler et al., 1994; Kessler, Sonnega, Bromet, Hughes, \& Nelson, 1995; Kessler et al., 1998). This comorbidity may be explained in a number of ways: firstly, it is possible that having one disorder increases the risk of developing another; alternatively, it is possible that anxiety and mood disorders may develop from the same underlying predisposition (Barlow, 2002).

In line with the notion that these disorders may develop from the same underlying predisposition, one possibility is that both of these disorders are underpinned by a similar cognitive process. For Brosschot, Gerin \& Thayer (2006) rumination and worry represent different but related manifestations of the same underlying cognitive process. The difference in these constructs is reflected in a different focus of "content" (e.g., future focussed in worry; past focussed in rumination); however, they are purported to share an underlying cognitive process which maintains psychophysiological arousal. This process is labelled 'perseverative cognition' and is defined as: "the repeated or chronic activation of the cognitive representation of one or more psychological stressors" (Brosschot et al., 2006, p.114). Our unique ability as humans means that we can look back and learn from the past, and we can look ahead to plan for the future; however, this may also lead to 'ruminating' about the past, or 'worrying' about the future (Brosschot, Verkuil \& Thayer, 2010). While psychological stressors themselves do not involve direct physical danger, they are composed of perceived threats to the physical or psychological integrity of the individual (Broschott et al., 2010). It is these cognitive representations, or thoughts, that result in a "fight-or-flight" response (Frijda, 1988), which is followed by a casade of biological and physiological changes in the body. These changes begin in the brain and cause peripheral responses to stress such as increased heart rate and blood pressure; and higher levels of stress hormones such as cortisol (Lovallo, 2004).

Evidence in the literature suggests that perseverative cognition (e.g., rumination and worry) in addition to having direct physiological effects, also mediates the prolonged effects of stressors. Some researchers have considered the relationship between rumination/worry and somatic disease or somatic complaints; with suggestive evidence for a prospective relationship. For example, Brosschot \& van den Doef (2006) reported that a total of 1 week's worry duration was prospectively related to health complaints in high school and college students. Trait 
rumination has been prospectively related to self-reported physical health issues one year later (Thomsen et al., 2004); and cross-sectional relationships have been found between trait rumination and health complaints (Lok \& Bishop 1999) and between frequency of worry about conflicting goals and somatisation (Emmons \& King, 1988). Furthermore, with regards to verifiable disease outcome, a tendency to worry has been shown to predict a second myocardial infarction (Kubzansky et al., 1997).

Other researchers have considered the relationship between worry/rumination and endocrine, neuroendocrine and physiological responses (e.g. cardiac activity; blood pressure). Chronic activation of the hypothalamic-pituitary-adrenal axis (predominantly cortisol release) is purported to increase an individual's susceptibility to many disease states. This is thought to be due to suppression of the immune system which has multiple pathological effects, e.g., dysregulation of metabolism and hippocampal degeneration (Brosschot et al., 2006). Several studies have shown that rumination and worry are associated with abnormal immune responses and elevated levels of cortisol. For example, trait rumination has been associated with higher morning salivary cortisol (Schlotz, Hellhammer, Schulz, \& Stone, 2004); and a higher number of several types of luekocytes (white blood cells of the immune system involved in defending the body against disease; Thomsen et al., 2004). Other studies have reported that participants reporting high levels of trait worry had fewer natural killer (NK) cells (Segerstrom, Solomon, Kemeny \& Fahey, 1998); and that high trait worry was related to suppression of an expected increase in NK cells when exposed to fear-evoking situations (Segerstrom, Glover, Craske \& Fahey, 1999).

People with chronically elevated heart rates (HR), and reduced heart rate variability (HRV; an indicator of parasympathetic activity), are at increased risk for all-cause mortality (Palatini \& Julius, 1997); and reduced HRV has also been associated with increased risk of developing hypertension and other cardiovascular disorders (Thayer \& Friedman, 2004; Stein \& Kleiger,1999). A sustained level of high blood pressure (BP) is also a risk factor for many diseases including cardiovascular disease (CVD) and diabetes (Schwartz et al., 2003). Researchers have shown that both dispositional measures of, and experimentally induced, worry are associated with low HRV and high HR (Lyonfields, Borkovec \& Thayer, 1995; Thayer, Friedman \& Borkovec, 1996). Furthermore, trait rumination has been associated with slower HR recovery after cognitive stress tasks (Roger \& Jamieson, 1988); and state, but not trait, worry has 
been related to high HR (Dua \& King, 1987). Elevated BP has also been associated with anticipation before emotional events in several studies; e.g., in students anticipating oral defence of their PhD (van Doornen \& van Blokland, 1992), prior to dental treatment (Brand et al., 1995), and mental arithmetic (Contrada, Wright \& Glass, 1984). In addition, multiple studies showed that emotional reactivity (which is strongly related to worry and rumination) was positively related to resting BP (Melamed, 1987), ambulatory BP (Melamed, 1996), and to high risk levels of lipids (fats) in blood plasma (Melamed, 1994).

Taken together, these findings appear to suggest that perseverative cognition (e.g., rumination, worry) is associated with decreased parasympathetic activity and increased sympathetic nervous system activity (Brosschott et al., 2006). Decreased parasympathetic activity suggests that rumination or worry are likely and independent risk factors for CVD; furthermore, low parasympathetic activity has also been found to characterise depression and anxiety disorders (Lyonfields et al., 1995; Thayer et al., 1996; Friedman \& Thayer, 1998; Friedman et al., 1993). Interestingly, depression and anxiety are increasingly documented as important risk factors for cardiovascular and other disorders (e.g., Kawachi et al., 1994; Wulsin, Vaillant \& Wells, 1999). Therefore it is possible that worry and rumination may serve as mediators of the relationship between anxiety and depression with CVD (Brosschot et al., 2006).

Another possibility is that anxiety and depression are underpinned by a shared mood trait such as negative affect (McLaughlin et al., 2007). Watson, Clark, \& Tellegen (1988) characterise negative affect (NA) as a general dimension of subjective distress and "unpleasurable engagement that subsumes a variety of aversive mood states" (p.1063); e.g., fear, nervousness, guilt, contempt, anger, disgust. Trait NA has been shown to roughly correspond to the personality factor anxiety/neuroticism; and Tellegen has also suggested that high levels of NA (both state and trait) are major distinguishing features of depression and anxiety, respectively (Tellegen, 1985). McLaughlin et al. (2007) suggest that this is the shared underlying factor which fosters rumination and/or worry. The positions of Brosschot et al. (2006) and McLaughlin et al. (2007) are compatible in as much as a predisposition to engage in perseverative cognition with a negative focus may potentially be causal in the development of anxiety and/or depression. Worry and rumination appear to worsen, not resolve, negative emotional states (Morrow \& Nolen-Hoeksema, 1990; Nolen-Hoeksema \& Morrow, 1993); furthermore, both forms of 
perseverative cognition are associated with over-general memory and a high level of abstract as opposed to concrete processing (e.g., Watkins \& Teasdale, 2001; Williams, 1996).

In a comprehensive review, Brosscot et al. (2006) suggested that perseverative cognition (e.g., rumination, worry) may be part of a causal chain that can lead to long-term health consequences, including cardiovascular disease and other chronic conditions and illnesses. A position that appears to be supported by the research presented above. Given the prevalence of perseverative cognition (e.g., rumination, worry) in the aetiology of different illnesses and conditions, it is important to understand what interventions may be useful in reducing the incidence of rumination and/or worry.

\subsection{Objectives}

The objective of this systematic review was to assess treatments used to reduce rumination and/or worry.

\subsection{Criteria for inclusion/exclusion}

Study aims and design. An initial review of the literature highlighted that there were very few studies explicitly designed to target rumination or worry. Therefore we expanded our inclusion criteria such that studies had to either: 1. explicitly treat rumination/worry; or 2. include secondary measures for the effects of treatment on rumination/worry. Studies in which rumination or worry was measured, but where they were only tested as mediators/moderators for changes in other study variables, were not included. The following study designs were eligible for inclusion: randomised controlled trials (RCT); randomised clinical controlled trials; clinical controlled trials; waitlist controlled trials; randomised trials; cohort studies; quasi-experimental studies.

Study status. Only articles from peer reviewed journals (January, 2002 - Dec, 2012) and written in English were eligible for inclusion. We limited our search to research published from 2002 to 2012 because we were interested in understanding the current landscape with regards to treatments utilised in the reduction of rumination and/or worry.

Participants. This review considered studies of adults ( $>18$ years of age) only. We included studies where participants were drawn from both clinical and non-clinical (e.g., general population, students) populations. Studies including participants with depression, anxiety (or a specific anxiety disorder, e.g., social phobia, generalised anxiety disorder, etc.) or a mixture of depression and anxiety were eligible for inclusion in the review. Studies including participants 
with learning disabilities or severe mental disorder (e.g., schizophrenia, bipolar disorder, depression with psychotic symptoms, psychosis, serious suicidal thoughts) or alcohol or substance abuse were not eligible for inclusion.

Types of outcome measures. Studies were eligible for inclusion if they utilised primary or secondary measures for rumination and/or worry: e.g., Ruminative Response Scale (RRS; Nolen-Hoeksema, 1991), or equivalent; Penn State Worry Questionnaire (PSWQ; Meyer, Miller, Metzger, \& Borkovec, 1990), or equivalent.

\subsection{Search strategy for identification of studies.}

The following electronic databases were examined in December, 2012: PsycINFO; PsycARTICLES; Medline; the Cochrane Library database of systematic reviews; and the Centre for Reviews and Dissemination (CRD) database.

The search in PsycInfo, PsycARTICLES and Medline made use of the following search terms: 1 Rumination; 2 Ruminat* AND thought(s) OR thinking; 3 Perseverative AND thought(s) OR thinking; 4 Repetitive AND thought(s) OR thinking; 5 Intrusive AND thought(s) OR thinking; 6 Negative AND thought(s) OR thinking; 7 Worry; 8 Worry AND thought(s) or thinking; 9 Anxi*; 10 Anxi* AND thought(s) OR thinking; 11 Stress AND thought(s) OR thinking; 12 Depress* AND thought(s) OR thinking; 13 \#1 OR \#2 OR \#3 OR \#4 OR \#5 OR \#6 OR \#7 OR \#8 OR \#9 OR \#10 OR \#11 OR \#12 AND “intervention” OR “randomis(z)ed controlled trial” OR "RCT” OR "Controlled trial” OR "Waitlist controlled trial” OR "Randomis(z)ed trial” OR “Cohort” OR "Quasi-experimental”. The search in CRD and Cochrane Library databases made use of the following terms: 1 Rumination; 2 Perseverative AND thought(s) OR thinking; 3 Repetitive AND thought(s) OR thinking; 4 Intrusive AND thought(s) OR thinking; 5 Negative AND automatic thought(s) OR thinking; 6 Worry; 7 Stress; 8 Depression AND thought(s) OR thinking.

Brackets indicate where search terms were entered twice with the different spellings. Search terms were selected based on common key terms identified during an initial search of the literature and related reviews.

\section{$\underline{\text { 2. Methods }}$}

The authors screened abstracts and titles of articles against the inclusion criteria and full text versions of potentially relevant articles were obtained for more detailed analysis. In total, 108 articles were obtained and reviewed. Of these, 89 were excluded from this review for the 
following reasons: not intervention study, no measure of rumination or worry (or rumination/worry measured but direct effects not reported), sample not adults, participants inappropriate, duplicate data (outcomes reported elsewhere), and sample too small (e.g., case studies). The remaining 19 articles were included in this review. Figure 3.1 shows a summary of study selection and exclusion.

Figure 3.1. Flow chart of study selection

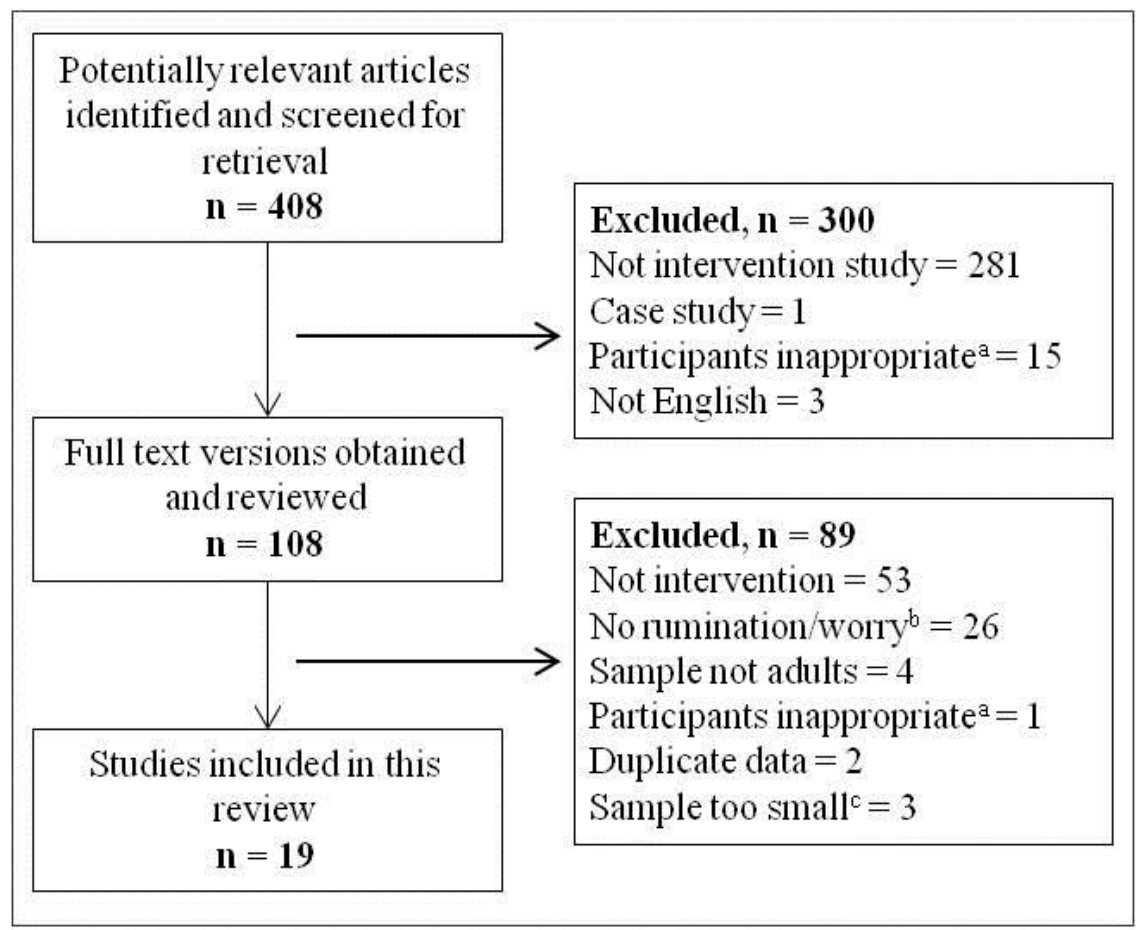

${ }^{a}$ learning disabled or severe mental illness; ${ }^{b}$ or rumination/worry measured but only used to test mediation or moderation; ${ }^{\mathrm{C}}$ case studies

\subsection{Description of included studies}

The search of the databases resulted in 19 articles meeting the inclusion criteria $(\mathrm{N}=1778)$. Details of included studies can be seen in Table 3.1, and details of treatment duration and protocols can be reviewed in Table 3.2. The majority of studies were described as randomised controlled trials ( $\mathrm{RCT} ; \mathrm{N}=15)$; two were studies described as waitlist controlled designs (WLC), and two studies were described as randomised designs (with no control group). Seven studies drew their participants from clinical environments (e.g., hospitals; GP practices); four studies utilized students; and eight studies were run with participants recruited from the general population. Measures of rumination and/or worry were included in the majority of 
studies as secondary measures. However, one study (Watkins et al., 2011) tested an intervention specifically designed to reduce rumination; and other studies stipulated that measuring change in rumination and/or worry was a primary aim (Andersson et al., 2012; Campbell, Labelle, Bacon, Faris, \& Carlson, 2012; Ekkers et al., 2011; Jain et al., 2007; Wolitzky-Taylor \& Telch, 2010). Most studies assessed change in either worry $(\mathrm{N}=9)$ or rumination $(\mathrm{N}=8)$, however two studies (Robins, Keng, Ekblad, \& Brantley, 2012; van Aalderen et al., 2012) assessed change in worry and rumination.

Table 3.1. Details of included studies

\begin{tabular}{|c|c|c|c|c|c|c|}
\hline Study & Country & $\begin{array}{l}\text { Study } \\
\text { type }\end{array}$ & Sample type & $\begin{array}{l}\text { Gender } \\
\text { mix }\end{array}$ & $\begin{array}{l}\text { Sample } \\
\text { size }\end{array}$ & $\begin{array}{l}\text { Attrition } \\
\text { Rate (N) }\end{array}$ \\
\hline Andersson et al. (2012) & Sweden & RCT & Clinical; GAD & mixed & $\mathrm{N}=81$ & $7 \%(6)$ \\
\hline Campbell et al. (2012) & Canada & WLC & Clinical; cancer patients & female & $\mathrm{N}=76$ & $17 \%(13)$ \\
\hline Ekkers et al. (2011) & Netherlands & $\mathrm{RCT}$ & Clinical; Dep; >65yrs & mixed & $\mathrm{N}=93$ & $26 \%(24)$ \\
\hline Feldman et al. (2010) & USA & Rand & Students & female & $\mathrm{N}=190$ & $0 \%$ \\
\hline Jain et al. (2007) & USA & $\mathrm{RCT}$ & Students & mixed & $\mathrm{N}=104$ & $22 \%(23)$ \\
\hline Leichsenring et al. (2009) & Germany & Rand & Clinical; GAD & mixed & $\mathrm{N}=57$ & $8 \%(5)$ \\
\hline Paxling et al. (2011) & Sweden & $\mathrm{RCT}$ & Gen Pop'n; GAD & mixed & $\mathrm{N}=89$ & $8 \%(7)$ \\
\hline Robins et al. (2012) & USA & WLC & Gen Pop'n & mixed & $\mathrm{N}=56$ & $26 \%(15)$ \\
\hline Robinson et al. (2010) & Australia & $\mathrm{RCT}$ & Gen Pop'n; GAD & mixed & $\mathrm{N}=150$ & $7 \%(12)$ \\
\hline Shapiro et al. (2008) & USA & $\mathrm{RCT}$ & Students & mixed & $\mathrm{N}=47$ & $6 \%(3)$ \\
\hline Steinmetz et al. (2012) & USA & $\mathrm{RCT}$ & Hurricane Ike survivors & mixed & $\mathrm{N}=56$ & $5.5 \%(10)$ \\
\hline Titov et al. (2010) & Australia & $\mathrm{RCT}$ & Gen Pop'n; GAD; PD; SP & mixed & $\mathrm{N}=86$ & $16 \%(14)$ \\
\hline Van Aalderen et al. (2012) & Netherlands & $\mathrm{RCT}$ & Clinical; Dep & mixed & $\mathrm{N}=205$ & $6 \%(14)$ \\
\hline Vollestad et al. (2011) & Norway & $\mathrm{RCT}$ & $\begin{array}{l}\text { Gen Pop'n; GAD; PD; } \\
\text { SAD }\end{array}$ & mixed & $\mathrm{N}=76$ & $14 \%(11)$ \\
\hline Watkins et al. (2009) & England & $\mathrm{RCT}$ & Gen Pop'n; Dys & mixed & $\mathrm{N}=60$ & $0 \%(0)$ \\
\hline Watkins et al. (2011) & England & $\mathrm{RCT}$ & Clinical; Dep & mixed & $\mathrm{N}=42$ & $9.5 \%(4)$ \\
\hline Watkins et al. (2012) & England & $\mathrm{RCT}$ & Clinical; Dep & mixed & $\mathrm{N}=121$ & $15 \%(18)$ \\
\hline Westra et al. (2009) & Canada & $\mathrm{RCT}$ & Gen Pop'n; GAD & mixed & $\mathrm{N}=76$ & $18 \%(14)$ \\
\hline $\begin{array}{l}\text { Wolitzky-Taylor \& Telch } \\
\text { (2010) }\end{array}$ & USA & $\mathrm{RCT}$ & Students; academic worry & mixed & $\mathrm{N}=113$ & $26 \%(29)$ \\
\hline
\end{tabular}

Study type: RCT=Randomised Controlled Trial; WLC=Waitlist Controlled Trial; Rand=multiple randomised treatment groups, no control group. Sample type: GAD=Generalised Anxiety Disorder diagnosis; PD=Panic Disorder diagnosis; $\mathrm{SP}=$ Social Phobia diagnosis; $\mathrm{SAD}=$ Social Anxiety Disorder diagnosis; Dys=dysphoria (subclinical low mood); Dep=Depression diagnosis; clinical=participants recruited from clinical environment (e.g. hospital; GP practice); Gen Pop'n=recruited from general population 


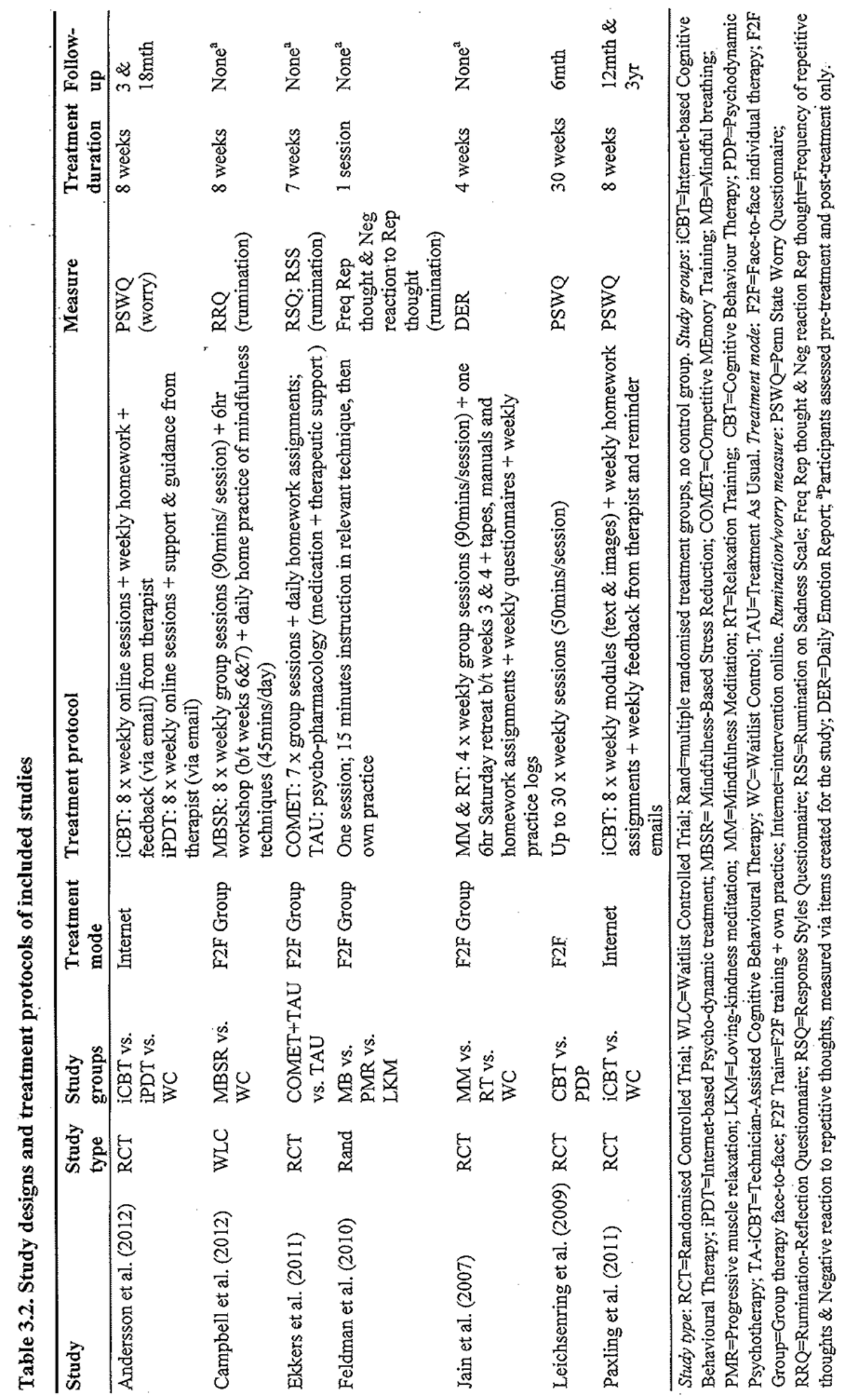




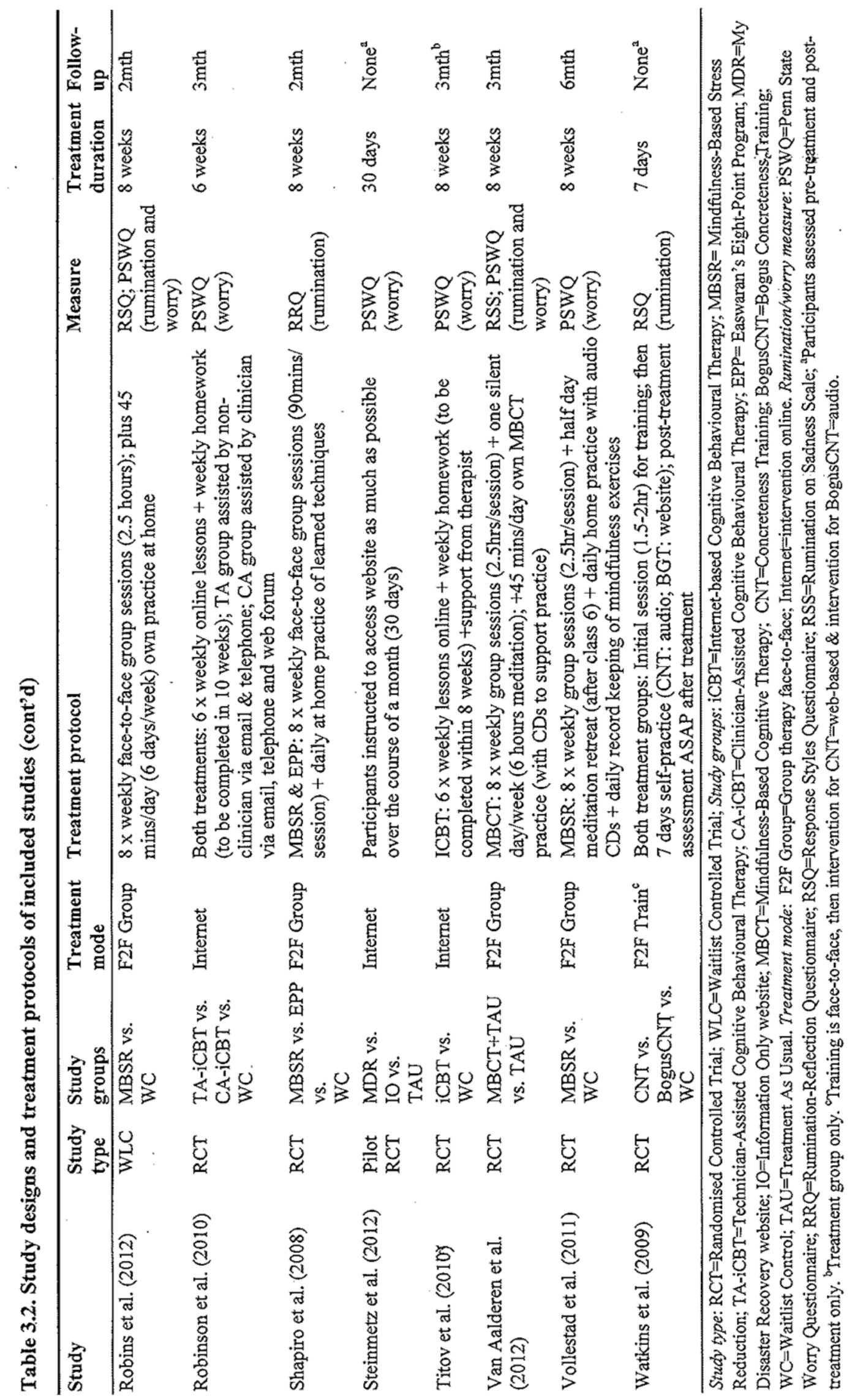




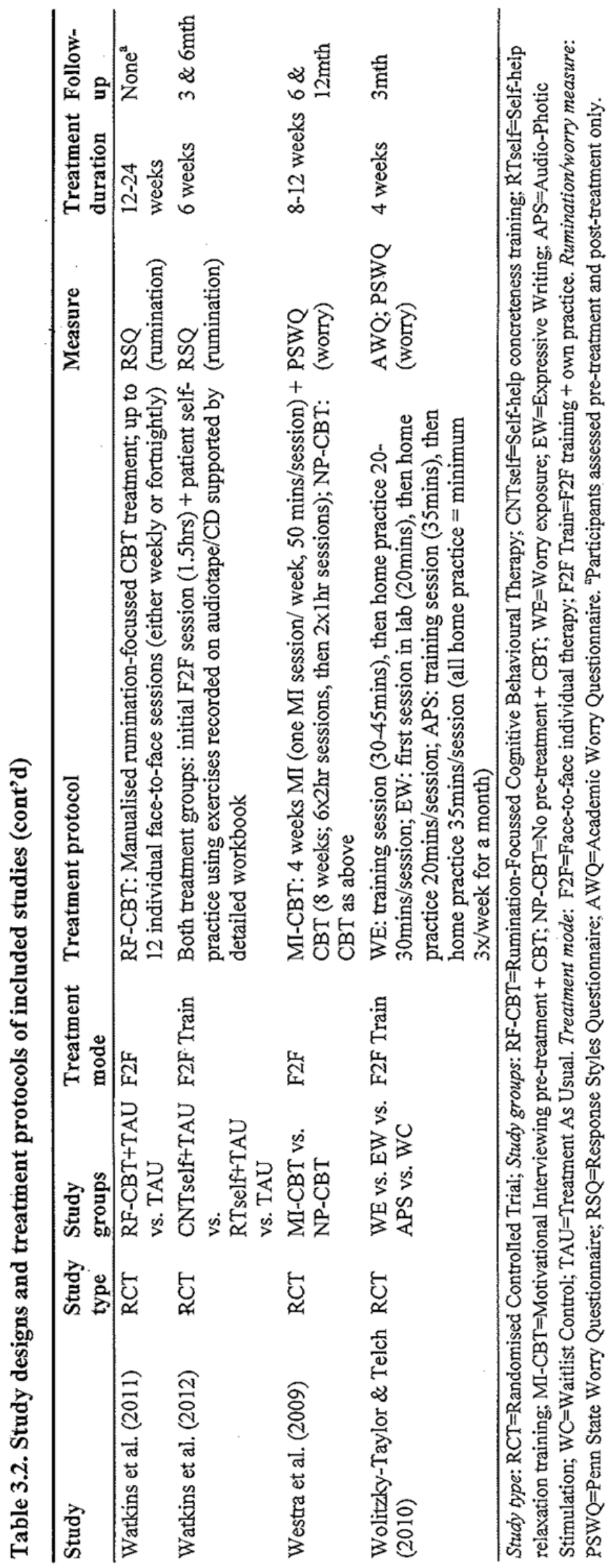


The majority of studies $(\mathrm{N}=14)$ assessed treatments that were delivered face-to-face either in group format or one-to-one; however, five studies assessed Internet-based interventions. Four of these studies assessed Internet-based cognitive behaviour therapy (iCBT) against other internet-based treatments (Andersson et al., 2012; Paxling et al., 2011; Robinson et al., 2010; Titov, Andrews, Johnston, Robinson, \& Spence, 2010); whilst the other study assessed a web tool (My Disaster Recovery website) which was developed specifically for survivors of Hurricane Ike in the USA (Steinmetz, Benight, Bishop, \& James, 2012), against an information only website. Andersson et al. (2012) compared iCBT with Internet-based psychodynamic treatment (iPDT) in participants with generalised anxiety disorder (GAD); Paxling et al. (2011) assessed the efficacy of iCBT against a waitlist control condition for participants with GAD; Robinson et al. (2010) compared the efficacy of clinician assisted iCBT to technician assisted iCBT in participants with GAD; and Titov et al. (2010) compared the efficacy of iCBT against a waitlist control condition for a mixed sample of anxiety disorders (GAD, social anxiety disorder [SAD], and panic disorder [PD]).

In the case of interventions delivered face-to-face, three studies compared CBT-based interventions against either waitlist control conditions or other interventions. Leichsenring et al. (2009) compared the efficacy of CBT against short-term psychodynamic psychotherapy for participants with GAD; Watkins et al. (2011) compared rumination-focussed CBT plus treatment as usual against treatment as usual alone in participants with depression; and Westra, Arkowitz, \& Dozois (2009) assessed the effect of adding motivational interviewing techniques to CBT for participants with GAD. Seven studies assessed mindfulness-based interventions against either waitlist control conditions or other treatments. Out of these seven studies, four studies assessed the efficacy of mindfulness-based stress reduction (MBSR). Campbell et al. (2012) assessed the effect of participation in MBSR on attention, rumination and resting blood pressure in female cancer patients; Robins et al. (2012) assessed the effect of participation in MBSR on emotional experience and expression; Shapiro, Oman, Thoresen, Plante, \& Flinders (2008) compared MBSR against another meditation-based relaxation programme - Easwaran's Eight Point Programme (EPP) - for change in mindfulness; and Vollestad, Sivertsen, \& Nielsen (2011) assessed the efficacy of MBSR in the treatment of anxiety. The remaining three studies assessed other mindfulness-based treatments. Specifically, Feldman, Greeson, \& Senville (2010) 
compared mindful-breathing, progressive muscle relaxation, and loving-kindness meditation for effect on negative reactions to repetitive thoughts; Jain et al. (2007) compared mindfulmeditation to relaxation training for their effects on distress, positive states of mind, rumination and distraction; and van Aalderen et al. (2012) assessed mindfulness-based cognitive therapy for the treatment of depression. Finally, in the remaining four studies, Ekkers et al. (2011) assessed competitive memory training (COMET) in the treatment of depression and rumination; Watkins, Baeyens, \& Read (2009) compared concreteness training (CNT) against bogus CNT for the treatment of dysphoria; Watkins et al. (2012) compared guided self-help concreteness training against guided self-help relaxation training in the treatment of depression; and Wolitzky-Taylor $\&$ Telch (2010) compared worry exposure against expressive writing and Audio-photic stimulation (APS) for the reduction of academic and general worry in students.

Treatment duration ranged from a single 90 minute session with testing immediately after the session (Feldman et al., 2010), to a maximum of 30 weeks of treatment (Leichsenring et al., 2009); however, in the majority of studies $(\mathrm{N}=15)$ treatment varied from 4 weeks to 8 weeks. For most studies, treatment occurred on a weekly basis, either through online modules to be completed in the internet-based treatments or through face-to-face sessions with therapists either in group format or one-to-one format. Change in rumination and/or worry scores was assessed pre- and post-treatment in all studies, and 12 studies also reported follow-up data. Follow-up periods ranged from two months to three years; however, most studies followed up between three and six months post-treatment.

\subsection{Methodological quality and treatment integrity}

The 19 studies included in this review were assessed by both authors separately; and then together. Any disagreements were resolved by discussion between the authors.

\section{Methodological quality of included studies}

We assessed the included studies against three criteria from Jadad et al. (1996; participants randomised; study described as double blinded; and withdrawals/drop-outs described; see Table 3.3, below), and against one other criterion developed by the authors for this study (quality of statistical analysis). We've made our assessment of the above criteria based on the information provided in the published studies. 
Table 3.3. Methodological quality of included studies

\begin{tabular}{|c|c|c|c|c|}
\hline Study name & $\begin{array}{c}\text { Participants } \\
\text { randomised? } \\
\qquad(0-2)\end{array}$ & $\begin{array}{c}\text { Study described as } \\
\text { double-blinded? } \\
(0-2)\end{array}$ & $\begin{array}{l}\text { Withdrawals/drop- } \\
\text { outs described? } \\
(0-1)\end{array}$ & $\begin{array}{c}\text { Total } \\
\text { score } \\
(0-5)\end{array}$ \\
\hline Andersson et al. (2012) & 2 & $0^{\mathrm{b}}$ & $0^{\mathrm{c}}$ & 2 \\
\hline Campbell et al. (2012) & $0^{\mathrm{a}}$ & $0^{\mathrm{b}}$ & 1 & $\mathbf{1}$ \\
\hline Ekkers et al. (2011) & 2 & $0^{\mathrm{b}}$ & 1 & 3 \\
\hline Feldman et al. (2010) & $0^{\mathrm{a}}$ & $0^{\mathrm{b}}$ & 0 & $\mathbf{0}$ \\
\hline Jain et al. (2007) & 2 & $0^{\mathrm{b}}$ & 1 & 3 \\
\hline Leichsenring et al. (2009) & $1^{\mathrm{d}}$ & $0^{\mathrm{b}}$ & 1 & 2 \\
\hline Paxling et al. (2011) & 2 & $0^{\mathrm{b}}$ & 1 & 3 \\
\hline Robins et al. (2012) & $1^{\mathrm{d}}$ & $0^{\mathrm{b}}$ & $0^{\mathrm{c}}$ & 1 \\
\hline Robinson et al. (2010) & 2 & $0^{\mathrm{b}}$ & $0^{\mathrm{c}}$ & 2 \\
\hline Shapiro et al. (2008) & $1^{\mathrm{e}}$ & $0^{\mathrm{b}}$ & 1 & 2 \\
\hline Steinmetz et al. (2012) & $1^{\mathrm{f}}$ & $0^{\mathrm{b}}$ & $0^{\mathrm{c}}$ & 1 \\
\hline Titov et al. (2010) & 2 & $0^{\mathrm{b}}$ & 0 & 2 \\
\hline Van Aalderen et al. (2012) & 2 & $0^{\mathrm{b}}$ & 1 & 3 \\
\hline Vollestad et al. (2011) & $1^{\mathrm{d}}$ & $0^{\mathrm{b}}$ & 1 & 2 \\
\hline Watkins et al. (2009) & $1^{\mathrm{d}}$ & $0^{\mathrm{b}}$ & $0^{\mathrm{c}}$ & 1 \\
\hline Watkins et al. (2011) & 2 & $0^{\mathrm{b}}$ & 1 & 3 \\
\hline Watkins et al. (2012) & 2 & $0^{\mathrm{b}}$ & 1 & 3 \\
\hline Westra et al. (2009) & 2 & $0^{\mathrm{b}}$ & $0^{\mathrm{c}}$ & 2 \\
\hline Wolitzky-Taylor \& Telch (2010) & 2 & $0^{\mathrm{b}}$ & $0^{\mathrm{c}}$ & 2 \\
\hline
\end{tabular}

Higher scores = better study quality; ${ }^{\mathrm{a}}$ No randomisation or method of randomisation not appropriate; ${ }^{\mathrm{b}} \mathrm{Not}$ described as double blinded; ${ }^{\mathrm{c}}$ No description of reasons for participants dropping out or withdrawing; ${ }^{\mathrm{d}}$ Study states participants randomly allocated to groups but provides no detail on process; ${ }^{\mathrm{e}} \mathrm{Good}$ randomisation process but participants allowed to change groups after randomisation due to schedule clashes; ${ }^{\mathrm{f}}$ Restricted randomisation

Participants randomised. According to Jadad et al. (1996): “A method to generate the sequence of randomization will be regarded as appropriate if it allowed each study participant to have the same chance of receiving each intervention and the investigators could not predict which treatment was next" (p.11). In this review, and in line with the guidelines from Jadad et al., if the study was described as randomised (which included the use of words such as randomly, random, and randomisation) we awarded the study one point. If the method of randomisation was 
described and it was appropriate (e.g., table of random numbers, computer generated, etc.) we gave the study an extra point; however, if the method of randomisation was described and it was inappropriate (e.g., methods of allocation using date of birth, date of admission, hospital numbers, or alternation), we deducted a point. The range of possible points for randomisation was $0-2$.

Eleven studies were awarded 2 points as their method of randomisation was well described and appropriate; two studies (Campbell et al., 2012; Feldman et al., 2010) received 0 points because they did not randomise participants; and six studies received 1 point for a number of reasons. Firstly, some of the studies stated that participants were randomised but did not provide detail on the randomisation process (Leichsenring et al., 2009; Robins et al., 2012; Vollestad et al., 2011; Watkins et al., 2009). These studies may have employed appropriate processes of randomisation but the lack of detail made it difficult for us to assess; and best practice suggests that randomisation processes should be reported in full. Secondly, one of the studies had a good randomisation process but then participants changed condition after randomisation had occurred (Shapiro et al., 2008); and finally, one study employed restricted randomisation (Steinmetz et al., 2012).

Study described as double-blinded. According to Jadad et al. (1996) "a study must be regarded as double blind if the words "double blind" are used" (p. 11). Where studies used the words "double blind" we awarded one point. We then gave an additional point if the method of double blinding was described and it was appropriate; however, where the method of double blinding was described and it was not appropriate, we deducted a point. Therefore the range of possible scores for this criterion was 0-2. None of the studies included in this review were described as double blinded and therefore all received 0 as their score for this criterion. This does not reflect poorly on the designs of these studies. In reality, it is often very difficult to achieve double-blinding in studies in which participants are receiving psychological therapeutic interventions, especially when these interventions are delivered to participants in groups.

Withdrawals / drop-outs described. According to Jadad et al. (1996) participants who were included in the study but did not complete treatment or who were not included in the analysis must be described. It is considered good practice to detail the number of withdrawals or drop-outs and to state the reasons for this. In order for a study to be awarded a point for this criterion, they must have included a statement with regards to withdrawals/drop-outs. Where a 
study has included no such detail they were not awarded a point. The range of possible points for this criterion is $0-1$. Ten studies received 1 point for this criterion. The remaining nine studies received 0 points as they did not include a statement with regards to reasons for participants withdrawing/dropping out.

Quality of statistical analysis. With regards to statistical analysis we were interested in the risk of introducing bias through the use of inappropriate techniques used when conducting intention-to-treat (ITT) analysis; or if the authors did not complete ITT analysis when a significant number of participants dropped out of treatment. In almost all randomised study designs, participants dropping out of treatment results in missing data. If there are only a few missing outcomes this will not be of major concern; however, when attrition rates are high, the method of dealing with missing data becomes important. Missing data is common and one review found that in approximately half of all RCTs outcomes were missing for more than $10 \%$ of participants (Wood, White, \& Thompson, 2004). If authors decide to omit data for participants whose data is incomplete, instead only analysing "completers" of treatment, this approach loses power, and bias may be introduced (Altman, 2009). Best practice dictates that ITT principles be adopted in all randomised trials. For example, the Consolidated Standards of Reporting Trials (CONSORT) statement for improving the quality of reports of RCTs states that all participants in each group should be analysed by "intention-to-treat” principles (Moher, Schulz, \& Altman, 2001). In an ITT analysis all randomised participants are included in the analysis in their allocated groups, irrespective of treatment adherence or completion (Altman, 2009).

When we assessed the 19 studies in this review against this criterion, we evaluated the following points: Was ITT analysis performed?; If ITT analysis was not performed, was this appropriate (i.e., no drop-outs)?; If ITT analysis was performed, what was the method used for data imputation?; If ITT analysis was performed, were the results from both the ITT and 'completer' samples reported? We also considered the attrition rate as studies with lower attrition rates would suffer less with regards to impact of data imputation. The majority of studies $(\mathrm{N}=15)$ stated that ITT analysis was performed. Out of the four studies which did not perform ITT analysis, in two studies (Feldman et al., 2010; Watkins et al., 2009), ITT analysis was not appropriate as the study design precluded attrition; however, the other two studies (Robins et al., 2010; Westra et al., 2009) only reported "completers" and this may have introduced significant bias in the results as the attrition rates were relatively high (26\% and $18 \%$ respectively). 
Therefore, these studies may have overestimated the efficacy of treatment and the results should be viewed with caution.

One of the main issues surrounding ITT analysis is how missing data is dealt with. One of the simplest and most commonly used method of imputing missing data is "last observation carried forward" (LOCF) analysis, in which missing final values of the outcome variable are replaced by the last known value before the participant was lost to follow-up. Even though this is a simple and easy method, there are strong grounds for not using it. LOCF assumes that the missing final value/s would be the same as the last recorded value/s; and this assumption is often implausible because dropping-out or withdrawing from treatment is likely to be associated with response to treatment (e.g., failure to respond; Altman, 2009). In studies of therapeutic or psychological treatments, often participants are assessed prior to treatment commencing, immediately after the end of treatment, and then they are followed up some time after treatment was finished (e.g., 6 months). If the last available observation is the pre-treatment observation (because the participant dropped out after randomisation but before treatment completion), there is obvious scope for the introduction of bias, especially when the participant attrition rate is high. Simple imputation methods (like LOCF) overestimate the reliability and precision of estimates, and the power of the study to assess the treatment. When data is missing, the sample size is reduced; however, simple imputation methods fail to take this into account and therefore tend to underestimate the variability of the results. There are other methods for imputing missing data (e.g., mixed model analyses; multiple imputation) which carry less risk of bias but these are more difficult to perform and thus, the LOCF method remains dominant.

In the studies in which ITT analysis was performed, nine studies (Campbell et al., 2012; Jain et al., 2007; Leichsenring et al., 2009; Robinson et al., 2010; Steinmetz et al., 2011; Titov et al., 2010; Vollestad et al., 2011; Watkins et al., 2011; Watkins et al., 2012) employed the LOCF method for data imputation; and five of these studies (Campbell et al., 2012; Jain et al., 2007; Titov et al., 2010; Vollestad et al., 2011; Watkins et al., 2012) had an attrition rate of greater than 10 percent. However, Jain et al. (2007) and Vollestad et al. (2011) evidenced best practice by reporting results for both 'completer' and ITT samples providing assurance that the attrition rate did not compromise reported results; and Watkins et al. (2011) and Watkins et al. (2012) conducted sensitivity analysis to ensure that drop-outs did not adversely affect their results. Therefore, these four studies have mitigated the risk of using LOCF method. Campbell et al. 
(2012) and Titov et al. (2010) only reported ITT sample results and both had relatively high attrition rates (17\% \& 16\% respectively); therefore their results may have been biased and should be viewed with caution. The remaining three studies using the LOCF method (Leichsenring et al., 2009; Robinson et al., 2010; Steinmetz et al., 2011) had relatively low attrition rates (8\%, 7\% and $5.5 \%$ respectively) therefore the risk of bias was quite low for these studies.

The remaining six studies which performed ITT analysis were considered low risk in terms of introducing bias. Five studies employed methods for data imputation that are more robust than LOCF, e.g., mixed model analyses or multiple imputation (Andersson et al. 2012; Ekkers et al., 2011; Paxling et al., 2011; Van Aalderen et al., 2012; Wolitzky-Taylor \& Telch, 2010); and two of these studies further evidenced best practice by reporting both 'completer' and ITT sample results (Paxling et al., 2011; Wolitzky-Taylor \& Telch, 2010). The remaining study (Shapiro et al., 2008) stated they performed ITT analysis but they did not clarify method of data imputation and they reported ITT results only; therefore, it was difficult to assess this study against this criterion. However, as they had a very low attrition rate (3\%), the risk of bias was considered low for this study.

\section{Treatment integrity of included studies}

Treatment integrity of included studies was assessed against two criteria from Foa \& Meadows (1997) gold standards for treatment integrity (valid and reliable measures; manualised, replicable, specific treatments) and a further criterion created for this study (intervention delivered consistently). Table 3.4 shows a summary of level of risk of bias for each of these criteria for each of the included studies; and we expand on the summarised data in the text below.

Foa \& Meadows (1997) suggest the use of measures with good psychometric properties. Because this systematic review aimed to assess the efficacy of treatments in the reduction of rumination and/or worry, we assessed the validity and reliability of rumination and/or worry measures included. Only one study (Feldman et al., 2010) has been classified as potentially high in risk of bias as this study stated that they created their 'repetitive thought' and 'reaction to repetitive thought' items for the purposes of the study. This is not a statement about the veracity of the created items; it is purely a reflection that this measure has not been validated in any other studies so we cannot be sure of its validity or reliability. All other studies were considered low risk as they employed well validated and reliable measures. With regards to worry, all eleven 
studies measuring worry used the Penn State Worry Questionnaire (PSWQ; Meyer et al., 1990). Regarding rumination, five studies used the Response Styles Questionnaire (RSQ; NolenHoeksema \& Morrow, 1991); two studies used the Rumination-reflection questionnaire (RRQ; Trapnell \& Campbell, 1999); one study used the Rumination on Sadness Scale (RSS; Raes, Hermans, \& Eelen, 2003); one study used the Daily Emotion Report (DER; Nolen-Hoeksema, Morrow \& Fredrickson, 1993); and one study created their own items.

Table 3.4. Assessment of treatment integrity in included studies

\begin{tabular}{|c|c|c|c|}
\hline Study name & $\begin{array}{c}\text { Valid and } \\
\text { reliable } \\
\text { measures?* }\end{array}$ & $\begin{array}{l}\text { Manualised, } \\
\text { replicable, specific } \\
\text { treatments?* }\end{array}$ & $\begin{array}{c}\text { Intervention } \\
\text { delivered } \\
\text { consistently? }\end{array}$ \\
\hline Andersson et al. (2012) & Low & Low & Low \\
\hline Campbell et al. (2012) & Low & Low & Low \\
\hline Ekkers et al. (2011) & Low & Low & Low \\
\hline Feldman et al. (2010) & $\operatorname{High}^{\mathrm{a}}$ & Low & Low \\
\hline Jain et al. (2007) & Low & Low & Low \\
\hline Leichsenring et al. (2009) & Low & Low & Low \\
\hline Paxling et al. (2011) & Low & Low & Low \\
\hline Robins et al. (2012) & Low & Low & Low \\
\hline Robinson et al. (2010) & Low & Low & Low \\
\hline Shapiro et al. (2008) & Low & Low & Low \\
\hline Steinmetz et al. (2012) & Low & Low & Low \\
\hline Titov et al. (2010) & Low & Low & Low \\
\hline Van Aalderen et al. (2012) & Low & Low & Low \\
\hline Vollestad et al. (2011) & Low & Low & Low \\
\hline Watkins et al. (2009) & Low & Low & Low \\
\hline Watkins et al. (2011) & Low & Low & Low \\
\hline Watkins et al. (2012) & Low & Low & Low \\
\hline Westra et al. (2009) & Low & Low & Low \\
\hline $\begin{array}{l}\text { Wolitzky-Taylor \& Telch } \\
\text { (2010) }\end{array}$ & Low & Low & Low \\
\hline
\end{tabular}

*Based on Foa \& Matthews' (1997) "gold standards" for treatment outcome trials; "criteria added for this systematic review; Low=low risk of bias; Unclear= insufficient detail to evaluate risk; High=high risk of bias; $\mathrm{n} / \mathrm{a}=$ not applicable to this study design; ${ }^{\mathrm{a}}$ Items created by the authors for this study so not validated or reliable 
Foa \& Meadows (1997) suggest the use of treatment protocol manuals to ensure consistency and all studies in this review satisfied this standard. All of the studies in this review used manualised or proceduralised processes for treatment; therefore all are considered low risk. However, the use of manualised treatment protocols does not necessarily translate into consistent delivery of treatment. We considered factors such as whether or not treatments had been assessed for adherence to treatment manuals and experience of treatment providers. We also considered whether or not the quality of face-to-face treatments had been assessed independently. We classified all of the studies included in this review as 'low risk' of bias with regards to intervention delivery. Some of the studies had the advantage of absolute consistency as the intervention was delivered online; however, even those studies where the intervention was delivered face-to-face either to participants individually or in groups were considered low risk due to rigorous standards and quality assessment.

\section{Results}

The following results represent a narrative synthesis of all included studies. Given the heterogeneous nature of the studies included in this review (e.g., participants drawn from different populations and varied interventions delivered in different formats) it was not appropriate or feasible to conduct a meta-analysis. Petticrew \& Gilbody (2004) suggest that studies with the best methodological quality should contribute more to the results of systematic reviews and this is the approach we adopted.

\subsection{Effects of treatment on self-reported rumination}

Ten out of the 19 studies reported results regarding effect of treatment on rumination. Six of these studies utilised mindfulness-based or relaxation-focussed treatments delivered in group format in face-to-face sessions. Campbell et al. (2012), Robins et al. (2012), and Shapiro et al. (2008) employed mindfulness-based stress reduction (MBSR); while Van Aalderen et al. (2012) assessed mindfulness-based cognitive therapy (MBCT). In the other two studies, Feldman et al. (2010) assessed mindful-breathing (MB) against progressive muscle relaxation (PMR) or lovingkindness-meditation (LKM); and Jain et al. (2007) assessed mindful-meditation (MM) against relaxation training $(\mathrm{RT})$.

Campbell et al. (2012) reported a significant reduction in rumination at the end of treatment for participants who had taken part in their eight-week MBSR programme when compared with participants in a waitlist control condition. However, this study did not randomise 
participants, and performed ITT analysis using LOCF with high attrition rates, therefore the results should be treated with caution. Robins et al. (2012) reported no significant reduction in rumination for participants in their eight week MBSR programme at the end of treatment; however, gains had been made by the MBSR over waitlist control group when participants were followed up two months post-treatment. As Robins et al. (2012) did not perform ITT analysis and only reported 'completers' (with a high rate of attrition) these results must also be viewed with caution. Shapiro et al. (2008) compared participation in an eight-week MBSR programme against another meditation-based programme (EPP) and found that increases in mindfulness (in the MBSR group) mediated a significant reduction in rumination, and MBSR was considerably more effective than EPP in reducing rumination. Furthermore, participants who had taken part in the MBSR programme showed further gains, through decreased levels of self-reported rumination, when followed-up two months after treatment. Randomisation was compromised in this study due to some participants changing condition after randomisation had been completed; however, this study was considered sound in other areas. Van Aalderen et al. (2012) reported that participants who had taken part in their eight-week MBCT programme reported significantly lower levels of rumination than participants in the waitlist control condition after treatment had ended.

Feldman et al. (2010) assessed change in negative reaction to repetitive thoughts (rumination); and concluded that participants who took part in mindful-breathing (MB) reported a significantly greater reduction in negative reaction to repetitive thoughts than those in the progressive muscle relaxation (PMR) or loving-kindness-meditation (LKM) conditions. Interestingly, in this study participants in the MB condition reported a significantly greater increase in repetitive thoughts than participants in either the PMR or LKM conditions. Jain et al. (2007) assessed mindful-meditation (MM) against relaxation training (RT) and found that participants in the MM group reported significantly less ruminative and distractive thoughts than participants in either the RT or waitlist control groups (which were not significantly different to one another).

The remaining four studies assessing change in self-reported rumination delivered their interventions via face-to-face format. Three of these studies were individual face-to-face treatment formats (Watkins et al., 2009; Watkins et al., 2011; and Watkins et al., 2012), whereas the final study delivered their training face-to-face in group format (Ekkers et al., 2011). Two 
studies (Watkins et al., 2009; Watkins et al., 2012) assessed concreteness training (CNT) which involves training individuals to be more concrete and specific in their thinking. In the study by Watkins et al. (2009), CNT was assessed against bogus CNT (BogusCNT = matched with CNT for treatment rationale, experimenter contact, and treatment duration but without the active "concrete thinking" component) for reduction of rumination in individuals with dysphoria (low mood). Participants attended an initial training session and then practiced the learned techniques for a period of seven days - with the support of audio CD exercises (CNT condition) or a website they could access (BogusCNT condition). After seven days, when participants were assessed, they found that participants in the CNT and BogusCNT groups reported significantly lower levels of self-reported rumination, when compared to participants in a waitlist control condition; and the two treatment groups were not significantly different to one another. In the other study, Watkins et al. (2012) assessed self-guided CNT (CNTself) against self-guided relaxation training (RTself) in the treatment of depressed individuals. Participants in this study attended for an initial training session and then practiced at home over the course of six weeks with the support of exercises recorded on audio CD and detailed workbooks. They found that participants from the CNTself condition reported significantly lower levels of rumination than participants in either the RTself or waitlist control conditions. Furthermore, when the self-help response became habitual (at follow-up); participants in the CNTself group reported significantly lower levels of rumination than participants in the RTself group.

Watkins et al. (2011) evaluated rumination-focussed CBT (RF-CBT) against a waitlist control condition in the treatment of depression. The duration of this treatment varied from 12 to 24 weeks depending on client need and results showed that participants taking part in the RFCBT programme reported significantly lower levels of rumination than those in the waitlist control condition after treatment was completed. Finally, Ekkers et al. (2011) considered the efficacy of competitive memory training (COMET) which is a seven-week cognitive behavioural intervention, involving weekly group sessions and homework, for the treatment of depression and rumination. COMET is designed to target underlying cognitive processes instead of the content of dysfunctional cognitions; therefore, its aim was to change the amount of involvement the patient has with their cognitions, rather than to change the negative emotions and thoughts themselves (Ekkers et al., 2011). They found that participants in the COMET condition reported 
significantly reduced levels of rumination when compared to the waitlist control group; and $27 \%$ of participants achieved a clinically significant reduction in rumination.

\subsection{Effects of treatment on self-reported worry}

Eleven out of the 19 included studies reported results with regards to change in selfreported worry. Six of these studies assessed treatments with a cognitive behaviour therapy (CBT) focus against either a waitlist control condition or other treatments (Andersson et al., 2012; Leichsenring et al., 2009; Paxling et al., 2011; Robins et al., 2012; Robinson et al., 2010; Titov et al., 2010; Westra et al., 2009). Out of these studies, four delivered their interventions via the Internet; while the other two studies delivered their interventions via individual face-to-face sessions (Leichsenring et al., 2009; Westra et al., 2009).

Andersson et al. (2012) evaluated an eight-week Internet-based CBT (iCBT) programme against an eight-week Internet-based Psychodynamic therapy (iPDT) programme. They found that participants in both the iCBT and iPDT conditions reported significantly lower self-reported worry than participants in a waitlist control group, and that there was no significant difference in treatment effectiveness between the Internet-delivered treatments. Furthermore, these differences were maintained at three month and 18 month follow-up. Paxling et al. (2011) and Titov et al. (2010) evaluated eight-week iCBT programmes against a waitlist control condition and found that worry was significantly reduced in those participants taking part in the iCBT programme in comparison to the waitlist control condition. Furthermore, these gains were maintained at followup: at three months (Titov et al., 2010), at 12 months and at three years (Paxling et al., 2011). However, results from the study by Titov et al. (2010) should be viewed with caution as the authors used the LOCF method in ITT analysis with a high attrition rate. Robinson et al. (2010) compared the efficacy of a six week Clinician-Assisted iCBT (CA-iCBT) programme to a six week Technician-Assisted iCBT (TA-iCBT) programme. They found that both treatments were equally effective at reducing worry when compared with the waitlist control group immediately post-treatment. Interestingly, at the three month follow-up, while the TA-iCBT had maintained treatment gains, the CA-iCBT group had made further gains.

Leichsenring et al. (2009) compared CBT to psychodynamic psychotherapy (PDP) and assessed worry as a secondary measure. Participants in this study attended weekly or fortnightly sessions with a CBT or psychodynamic therapist for up to 30 weeks. They found that participants in the CBT group reported significantly lower levels of self-reported worry than participants in 
the PDP condition; and that treatment gains were maintained at six month follow-up. In the study by Westra et al. (2009), the effect of adding motivational interviewing prior to CBT (MI-CBT) was assessed against CBT with no pre-treatment (NP-CBT). All participants attended an eightweek CBT programme conducted through individual face-to-face sessions with a CBT therapist; however, participants in the MI-CBT group additionally had 4 weekly sessions of motivational interviewing treatment prior to commencing their CBT programme. Results showed that participants in the MI-CBT reported significantly lower levels of self-reported worry than those in the NP-CBT group. Interestingly, the authors reported that MI-CBT appeared most effective for participants with the highest worry scores at baseline; and whilst there was some evidence of relapse at six month follow-up, when participants were followed up at 12 months, treatment gains were again evident. However, this study reported results for 'completers' only and had a relatively high attrition rate, therefore their findings may be inflated and the results should be viewed with caution.

Two of the remaining four studies (Robins et al., 2012; Vollestad et al., 2011) assessed eight-week MBSR programmes, delivered via group face-to-face sessions, against waitlist control conditions. Both studies reported significant reduction in self-reported worry for participants from the MBSR group versus those in the waitlist control condition; furthermore, treatment gains were maintained at follow-up in both studies. However, the results from Robins et al. (2012) should be viewed with caution as they did not conduct ITT analysis in spite of the fact that they had a high rate of attrition (26\%); and this may have resulted in an overestimation of treatment effect. Steinmetz et al. (2012) assessed the efficacy of a specialist website - My Disaster Recovery (MDR) - designed to help survivors of Hurricane Ike increase coping selfefficacy, against an information only (IO) website and waitlist control condition. The same information was essentially presented in both conditions; however, in the MDR site, participants enjoyed a more interactive experience (e.g., through self-tests and video vignettes). Participants were encouraged to access the sites as much as possible over a period of 30 days. After 30 days, results showed that participants in the MDR condition reported significantly reduced selfreported worry that those participants accessing the IO website or in the waitlist control condition.

In one of the remaining two studies, Van Aalderen et al. (2012) reported that participants who had taken part in their eight-week MBCT programme reported significantly lower levels of 
self-reported worry than participants in the waitlist control condition after treatment had ended. The final study (Wolitzky-Taylor \& Telch, 2010) evaluated worry exposure (WE), expressive writing (EW), and Audio-Photic Stimulation (APS) against a waitlist control condition for the reduction in self-reported academic and general worry. Audio-photic stimulation (APS) - also called Audio-visual entrainment (AVE) - is a form of therapy used to promote relaxation and treat stress-related disorders (Wolitzky-Taylor \& Telch, 2010). In the current study APS was delivered via a device consisting of an iPod-sized control panel which connected into headphones emitting a programmable pulsing sound (similar to that of a beating heart) and sunglasses that emit programmable bursts of orange flickering light (Wolitzky-Taylor \& Telch, 2010). All treatments comprised of an initial face-to-face training session and then self-practice over the course of four weeks. Results showed that WE and APS were significantly more effective than EW (which did not differ significantly from the waitlist control condition) at posttreatment. At follow-up (three months), all treatments had maintained gains; however, participants in the EW condition had made the most significant improvement with regards to reduction in worry, potentially suggesting a delayed treatment effect. Summarised results for all included studies can be viewed in Table 3.5.

Table 3.5. Summarised results of all included studies

\begin{tabular}{|c|c|c|c|}
\hline Study & Study Groups & Follow-up? & Rumination/worry findings \\
\hline $\begin{array}{l}\text { Andersson et } \\
\text { al. (2012) }\end{array}$ & $\begin{array}{l}\text { iCBT vs. } \\
\text { iPDT vs. } \\
\text { WC }\end{array}$ & $\begin{array}{l}3 \mathrm{mth} \& \\
18 \mathrm{mth}\end{array}$ & $\begin{array}{l}\text { Worry: post-treatment - significant reduction in worry for both } \\
\text { treatment groups in comparison to control (no significant difference } \\
\text { between ICBT and IPDT groups); at } 3 \mathrm{mth} \text { follow-up - same as } \\
\text { post-treatment; } 18 \text { mth follow-up - significant difference from pre- } \\
\text { to } 18 \mathrm{mth} \text { follow-up for ALL groups }\end{array}$ \\
\hline $\begin{array}{l}\text { Campbell et al. } \\
(2012)\end{array}$ & $\begin{array}{l}\text { MBSR vs. } \\
\text { WC }\end{array}$ & None & $\begin{array}{l}\text { Rumination: MBSR group reported significantly lower levels of } \\
\text { rumination than WLC group }\end{array}$ \\
\hline $\begin{array}{l}\text { Ekkers et al. } \\
(2011)\end{array}$ & $\begin{array}{l}\text { COMET+TAU } \\
\text { vs. TAU }\end{array}$ & None & $\begin{array}{l}\text { Rumination: Patients in TAU+COMET condition reported } \\
\text { significantly reduced rumination when compared with control group } \\
\text { for both rumination measures; } 27 \% \text { of patients achieved clinically } \\
\text { significant reduction in rumination }\end{array}$ \\
\hline
\end{tabular}

Study groups: iCBT=Internet-based Cognitive Behaviour Therapy; iPDT=Internet-based Psycho-dynamic treatment; MBSR= Mindfulness-Based Stress Reduction; COMET=COmpetitive MEmory Training; WC=Waitlist Control; TAU=Treatment As Usual. 
Table 3.5. Summarised results of all included studies (cont'd)

\begin{tabular}{|c|c|c|c|}
\hline Study & Study Groups & Follow-up? & Rumination/worry findings \\
\hline $\begin{array}{l}\text { Feldman et al. } \\
\text { (2010) }\end{array}$ & $\begin{array}{l}\text { MB vs. PMR vs. } \\
\text { LKM }\end{array}$ & None & $\begin{array}{l}\text { Repetitive thought: Negative reaction to repetitive thoughts is } \\
\text { reduced in the MB condition relative to the other two conditions; } \\
\text { increased frequency of repetitive thoughts in the MB vs. other } \\
\text { two conditions; however, decreased levels of negative reaction } \\
\text { to repetitive thoughts in MB condition }\end{array}$ \\
\hline $\begin{array}{l}\text { Jain et al. } \\
(2007)\end{array}$ & MM vs. RT vs. WC & None & $\begin{array}{l}\text { Rumination and distraction: Participants in the MM group } \\
\text { showed significantly greater reduction in ruminative and } \\
\text { distractive thoughts to those in the RT and control groups, which } \\
\text { were not significantly different to each other }\end{array}$ \\
\hline $\begin{array}{l}\text { Leichsenring et } \\
\text { al. (2009) }\end{array}$ & PDP vs. CBT & $6 \mathrm{mths}$ & $\begin{array}{l}\text { Worry: CBT significantly more effective than psychodynamic } \\
\text { psychotherapy at reducing symptoms of worry; treatment effects } \\
\text { maintained at } 6 \mathrm{mth} \text { follow-up }\end{array}$ \\
\hline $\begin{array}{l}\text { Paxling et al. } \\
(2011)\end{array}$ & iCBT vs. WC & $\begin{array}{l}12 \mathrm{mth} \& \\
3 \text { years }\end{array}$ & $\begin{array}{l}\text { Worry: significantly reduced for those in the guided Internet- } \\
\text { delivered CBT condition vs. WLC; treatment effects maintained } \\
\text { at } 1 \mathrm{yr} \text { and } 3 \mathrm{yr} \text { follow-up }\end{array}$ \\
\hline $\begin{array}{l}\text { Robins et al. } \\
(2012)\end{array}$ & MBSR vs. WC & $2 \mathrm{mths}$ & $\begin{array}{l}\text { Rumination: no significant difference for MBSR group from } \\
\text { pre- to post-treatment; however, significant difference between } \\
\text { pre-treatment and follow-up as MBSR and waitlist groups } \\
\text { combined (after WL group completed MBSR training) } \\
\text { Worry: significant reduction pre- to post-treatment; and pre- to } \\
\text { follow-up }\end{array}$ \\
\hline $\begin{array}{l}\text { Robinson et al. } \\
(2010)\end{array}$ & $\begin{array}{l}\text { CA-iCBT vs. TA- } \\
\text { iCBT vs. WC }\end{array}$ & $3 \mathrm{mths}$ & $\begin{array}{l}\text { Worry: At post-treatment both treatment groups equally } \\
\text { efficacious at reducing worry symptoms - no change in WLC } \\
\text { group; At } 3 \text { mth follow-up TA assisted group has maintained } \\
\text { treatment gains, CA assisted group has made further gains }\end{array}$ \\
\hline $\begin{array}{l}\text { Shapiro et al. } \\
(2008)\end{array}$ & $\begin{array}{l}\text { MBSR vs. EPP vs. } \\
\text { WC }\end{array}$ & $2 \mathrm{mths}$ & $\begin{array}{l}\text { Rumination: Increases in mindfulness mediated a significant } \\
\text { reduction in rumination in MBSR participants; further gains } \\
\text { made at follow-up }\end{array}$ \\
\hline $\begin{array}{l}\text { Steinmetz et al. } \\
(2012)\end{array}$ & $\begin{array}{l}\text { MDR vs. IO vs. } \\
\text { usual care (control) }\end{array}$ & None & $\begin{array}{l}\text { Worry: MDR website significantly better at reducing self- } \\
\text { reported worry than information only or usual care }\end{array}$ \\
\hline $\begin{array}{l}\text { Titov et al. } \\
(2010)\end{array}$ & $\begin{array}{l}\text { iCBT vs. } \\
\text { WC }\end{array}$ & $\begin{array}{l}3 \text { mths } \\
\text { (treatment } \\
\text { group only) }\end{array}$ & $\begin{array}{l}\text { Worry: Significant reduction in worry for ICBT group from pre- } \\
\text { treatment to post-treatment and from pre-treatment to follow-up }\end{array}$ \\
\hline $\begin{array}{l}\text { Van Aalderen } \\
\text { et al. (2012) }\end{array}$ & $\begin{array}{l}\text { MBCT+TAU vs. } \\
\text { TAU }\end{array}$ & $3 \mathrm{mths}$ & $\begin{array}{l}\text { Rumination and worry: MBCT+TAU group significantly } \\
\text { reduced levels of rumination and worry than TAU group }\end{array}$ \\
\hline $\begin{array}{l}\text { Vollestad et al. } \\
(2011)\end{array}$ & $\begin{array}{l}\text { MBSR vs. } \\
\text { WC }\end{array}$ & $6 \mathrm{mths}$ & $\begin{array}{l}\text { Worry: significant reduction in self-reported worry for those in } \\
\text { MBSR condition vs. WLC; treatment gains maintained at } 6 \mathrm{mth} \\
\text { follow-up }\end{array}$ \\
\hline
\end{tabular}

Study groups: $\mathrm{MB}=$ Mindful breathing; PMR=Progressive muscle relaxation; LKM=Loving-kindness meditation; $\mathrm{MM}=$ Mindfulness Meditation; RT=Relaxation Training; CBT=Cognitive Behaviour Therapy; PDP=Psychodynamic Psychotherapy; iCBT=Internet-based Cognitive Behaviour Therapy; TA-iCBT=Technician-Assisted iCBT; CA$\mathrm{iCBT}=\mathrm{Clini}$ cian-Assisted iCBT; EPP= Easwaran's Eight-Point Program; MDR=My Disaster Recovery website; $\mathrm{IO}=$ Information Only website; MBSR= Mindfulness-Based Stress Reduction; MBCT=Mindfulness-Based Cognitive Therapy; WC $=$ Waitlist Control; TAU=Treatment As Usual. 
Table 3.5. Summarised results of all included studies (cont'd)

\begin{tabular}{|c|c|c|c|}
\hline Study & Study Groups & Follow-up? & Rumination/worry findings \\
\hline $\begin{array}{l}\text { Watkins et al. } \\
\text { (2009) }\end{array}$ & $\begin{array}{l}\text { CNT vs. } \\
\text { BogusCNT vs. } \\
\text { WC }\end{array}$ & None & $\begin{array}{l}\text { Rumination: significantly reduced rumination in the CNT \& } \\
\text { BogusCNT conditions vs. WLC; however, there was no } \\
\text { significant difference between CNT \& BogusCNT groups }\end{array}$ \\
\hline $\begin{array}{l}\text { Watkins et al. } \\
\text { (2011) }\end{array}$ & $\begin{array}{l}\text { RF-CBT vs. } \\
\text { WC }\end{array}$ & None & $\begin{array}{l}\text { Rumination: Participants in the RFCBT group significantly } \\
\text { lower levels of self-reported rumination at post-treatment when } \\
\text { compared with those in WLC }\end{array}$ \\
\hline $\begin{array}{l}\text { Watkins et al. } \\
\text { (2012) }\end{array}$ & $\begin{array}{l}\text { TAU (control) vs. } \\
\text { TAU+CNTself vs. } \\
\text { TAU+RTself }\end{array}$ & $\begin{array}{l}3 \text { mths \& } \\
6 \mathrm{mths}\end{array}$ & $\begin{array}{l}\text { Rumination: at post-treatment TAU+CNTself resulted in } \\
\text { significantly reduced levels of self-reported rumination than } \\
\text { TAU or TAU+RTself; TAU+CNTself was significantly more } \\
\text { effective than TAU+RTself when self-help response became } \\
\text { habitual }\end{array}$ \\
\hline $\begin{array}{l}\text { Westra et al. } \\
(2009)\end{array}$ & $\begin{array}{l}\text { MI-CBT vs. } \\
\text { NP-CBT }\end{array}$ & $\begin{array}{l}6 \mathrm{mths} \& \\
12 \mathrm{mths}\end{array}$ & $\begin{array}{l}\text { Worry: MI-CBT group showed significantly greater reduction in } \\
\text { worry than CBT alone (NP-CBT) }\end{array}$ \\
\hline $\begin{array}{l}\text { Wolitzky- } \\
\text { Taylor \& Telch } \\
(2010)\end{array}$ & $\begin{array}{l}\text { WE vs. } \\
\text { EW vs. } \\
\text { APS vs. } \\
\text { WC }\end{array}$ & $3 \mathrm{mths}$ & $\begin{array}{l}\text { Academic worry \& General worry: WE and APS were } \\
\text { significantly more effective than EW which did not differ } \\
\text { significantly from WLC post-treatment. At follow-up, all } \\
\text { treatments maintained gains; however, EW made the most } \\
\text { significant gain }\end{array}$ \\
\hline
\end{tabular}

Study groups: CNT=Concreteness Training; BogusCNT=Bogus Concreteness Training; RF-CBT=Rumination-Focussed Cognitive Behavioural Therapy; CNTself=Self-help concreteness training; RTself=Self-help relaxation training; MI-

$\mathrm{CBT}=$ Motivational Interviewing pre-treatment $+\mathrm{CBT}$; NP-CBT=No pre-treatment $+\mathrm{CBT}$; MI-CBT=Motivational Interviewing pre-treatment + CBT; NP-CBT=No pre-treatment + CBT; WE=Worry exposure; EW=Expressive Writing; APS=Audio-Photic Stimulation; WC=Waitlist Control.

\section{Discussion}

This systematic review aimed to assess treatments utilised for the reduction of rumination and/or worry. Most of the studies included in the review evidenced fair to excellent methodological quality and treatment integrity. Nevertheless, there were a few studies for which we suggest results should be viewed with caution, predominantly due to the quality of statistical analysis. Robins et al. (2010) and Westra et al. (2009) did not conduct ITT analysis, choosing only to report findings from "completers" of treatment. In the context of significant attrition rates in these two studies (26\% and $18 \%$ respectively), there is a risk that effect sizes have been overestimated. Campbell et al. (2012) and Titov et al. (2010) did conduct ITT analysis but chose to do so using the LOCF method for imputation of missing data. If their attrition rates had been low, the risk of bias would also be very low; however, their attrition rates were relatively high (17\% and $16 \%$ respectively), therefore we also view their results with caution. Whilst LOCF is not the only method for the imputation of missing data, it is still the most widely used; however, 
given repeated warnings about the dangers of using the LOCF method it seems clear that its use as the sole form of analysis should be discontinued (Lane, 2008; Shapiro, 2001; Barnes, Mallinckrodt, Lindborg, \& Carter, 2008; Streiner, 2002).

Furthermore, the heterogeneous nature of the included studies may make generalisation difficult. For example, the studies included samples drawn from clinical, general adult and student populations; and employed various interventions delivered in different formats. This means that we could not compare effect sizes using meta-analyses as we may well expect the effect sizes of treatment, due to baseline differences in symptoms, and differences in ability to engage with treatment, to be quite different from each other. However, as our aim was to assess treatments used in the reduction of rumination and/or worry, and the majority of studies used the same well-validated measures for these constructs, we maintain they can be assessed against each other narratively. It is worth noting also that many of the studies included in this review reported substantially lower dropout rates than those reported in comparable studies in the clinical literature. For example, a recent meta-analysis reported average dropout rates of between $18 \%$ and $20 \%$ for psychodynamic or CBT-based treatments (Swift \& Greenberg, 2012). This may be reflective of the difference study populations included and may reflect a higher level of baseline functioning in the participants included in these studies. It may be that some of the treatments which appear effective here may be less effective if participants were showing greater symptom severity at baseline. However, this is speculation and a detailed analysis of the difference in efficacy of treatment in different populations, whilst beyond the scope of this systematic review, presents an interesting avenue for future research.

In spite of these limitations, this systematic review suggests that mindfulness-based and cognitive behavioural interventions may be useful in the treatment or reduction of both rumination and worry. Irrespective of delivery mode, both Internet-delivered and face-to-face delivered formats appear to be useful. However, it is worth noting that most of the Internetdelivered interventions in this review were CBT-based interventions. Whether or not mindfulness-based interventions would be as effective if delivered via the Internet is worthy of further exploration. Treatments in which participants are encouraged to change their thinking style, or to disengage from emotional response to rumination or worry (e.g., through mindful techniques), may be helpful. For example, treatments which enable participants to adopt more concrete and specific thinking (Watkins et al., 2009; Watkins et al., 2012), or which cognitively 
restructure thinking in a more positive and constructive way (e.g., through CBT), appear to reduce rumination and worry. Perhaps interventions which require active mental engagement are useful because active mental engagement interferes with the more passive cognitive processes of rumination and/or worry? However, this is speculation and also requires further empirical work.

Within the literature, worry, rumination, and many other cognitive processes (e.g., anticipatory stress; intrusive thoughts) are generally considered to be separate constructs, conceptually close but not equated with one another (Brosschot et al., 2006). This is not our position. We believe they are linked and are potentially underpinned by the same cognitive process, that of perseverative cognition (Brosschot et al., 2006). If this is the case, we would expect to see similar treatments proving effective for conditions for which worry and/or rumination are key components (e.g., depression and anxiety disorders). Findings from the studies included in this review may offer support for our position as similar formats of intervention appear to be helpful in reducing self-reported rumination and/or worry. There were two studies which measured the change in both rumination and worry (Robins et al., 2012; Van Aalderen et al., 2012) and in both of these studies rumination and worry were reduced by the same intervention. If rumination and worry represent different manifestations of perseverative cognition (Brosschot et al., 2006), it is possible that treatments are working by interfering with this process, thereby reducing both rumination and worry; however, we do accept that there are also potentially other explanations for this and, as mentioned above, this provides an interesting avenue for future research. In addition, this review has not explored in detail the components of the included studies to reach an understanding of the specific shared mechanisms of the effective treatments; another avenue for future research.

Interestingly, in the study by Feldman et al. (2010), the authors did not seek to reduce rumination; instead, the focus was on the reduction of negative evaluation of repetitive thoughts. Likewise, the study by Ekkers et al. (2011) aimed to reduce participants' involvement with their cognitions, rather than to reduce cognitions in general or to change anything content-related. This suggests that rumination and/or worry per se may not be the issue but that an individual's emotional response to the process of perseverative cognition may be more of a problem. This position is supported by a recent study in the occupational health literature which measured two distinct but related forms of work-related rumination - affective rumination and problem-solving pondering - in a large sample ( $=719)$ of working adults (Querstret \& Cropley, 2012). The 
authors suggested that affective rumination (characterised by negatively emotionally-valenced perseverative cognitions) would potentially be more detrimental than problem-solving pondering (characterised by perseverative cognitions without an emotional component) in the context of recovery from work-related demands (stressors). They found that affective rumination was significantly more predictive of both acute (short-term) and chronic (persistent; long-term) workrelated fatigue. The results of this study have been further bolstered by findings from a longitudinal follow-up which suggested affective rumination may be part of a causal model of work-related fatigue (Querstret \& Cropley, in preparation). In line with the perseverative cognitions hypothesis (Brosschot et al., 2006), the authors posited that affective rumination may maintain psychophysiological arousal whereas problem-solving pondering may not. They have speculatively suggested that these different forms of work-related rumination may operate differentially in the brain with problem-solving pondering having a dampening effect (via the prefrontal cortex) of the emotional response. This raises an avenue worthy of future research. If rumination and/or worry per se are not as problematic as the individual's emotional evaluation of these processes, perhaps interventions designed to change emotional interpretation would be just as effective as studies which aim to reduce rumination and/or worry.

In the studies included in this review, the majority of CBT-based interventions were supported by trained clinicians; however, the results from Robinson et al. (2010) suggest that, in the short-term, iCBT may reduce worry when supported by non-clinicians. However, at followup those participants who had been managed by non-clinicians did not maintain gains in the same way as those who had support from trained therapists. This seems to suggest that a model for lasting treatment effect requires at least some training in the respective techniques for those delivering or supporting the respective interventions. In the context of improving access to psychological therapies, it would be advantageous to be able to develop and implement treatments that were effective without the need for expensive therapeutic support. This is an avenue worthy of future exploration.

There is a possibility of publication bias in this review as the articles included all came from peer reviewed journals; and Petticrew \& Roberts (2006) suggest it is more likely that the articles published would have concluded that the intervention was effective. Also, because the search for articles was limited to a specific time period (2002-2012), it is possible that contradictory results have been missed which could have added to this review. However, the 
objective of this review was to understand the current landscape with regards to available treatments.

\section{Conclusions}

This systematic review suggests that mindfulness-based and cognitive behavioural interventions may be effective in the reduction of both rumination and worry. Irrespective of delivery mode, both Internet-delivered and face-to-face delivered formats appear to be useful. More broadly, treatments in which participants are encouraged to change their thinking style, or

to disengage from their emotional response to rumination and/or worry (e.g., through mindful techniques), could be helpful. 


\section{References}

Altman, D. (2009). Missing outcomes in randomized trials: addressing the dilemma. Open Medicine, 3. Available at: http://www.openmedicine.ca/article/view/323/232. Date accessed: 05 Mar, 2013.

Barlow, D.H. (2002). Anxiety and its disorders: The nature and treatment of panic, 2nd ed. New York: The Guilford Press.

Barlow, D. H., \& DiNardo, P. A. (1991). The diagnosis of generalized anxiety disorder: Development, current status, and future directions. In R. M. Rapee, \& D. H. Barlow (Eds.), Chronic anxiety: Generalized anxiety disorder and mixed anxiety-depression (pp. 95-118). New York: Guilford Press.

Barnes, S.A., Mallinckrodt, C.H., Lindborg, S.R., \& Carter, M.K. (2008). The impact of missing data and how it is handled on the rate of false-positive results in drug development. Pharmaceutical Statistics, 7, 215-225.

Borkovec, T.D., Robinson, E., Pruzinsky, T., \& DePree, J.A. (1983). Preliminary exploration of worry: some characteristics and processes. Behaviour Research and Therapy, 21, 9-16.

Borkovec, T.D, Ray, W.J, \& Stober, J. (1998) Worry: a cognitive phenomenon intimately linked to affective, physiological, and interpersonal behavioral processes. Cognitive Therapy and Research, 22, 561- 76.

Brand, H.S., Gortzak, R.A., Palmer-Bovba, C.C., Abraham, R.E., \& Abraham-Inpijn, L. (1995). Cardiovascular and neuroendocrine responses during acute stress induced by different types of dental treatment. International Dental Journal, 45, 45-48.

Brosschot, J.F., Gerin, W., \& Thayer, J.F. (2006). The perseverative cognition hypothesis: A review of worry, prolonged stress-related physiological activation and health. Journal of Psychosomatic Research, 60, 113-124.

Brosschot, J.F., \& van den Doef, M. (2006). Daily worrying increases somatic complaints; a simple worry reduction intervention helps. Psychology and Health, 21, 19-31.

Brosschot, J.F., Verkuil, B., \& Thayer, J.F. (2010). Conscious and unconscious perseverative cognition: Is a large part of prolonged physiological activity due to unconscious stress? Journal of Psychosomatic Research, 69, 407-416.

Brown, T.A., \& Barlow, D.H. (1992). Comorbidity among anxiety disorders: Implications for treatment and DSM-IV. Journal of Consulting and Clinical Psychology, 60, 835-844. 
Brown, T.A., Campbell, L.A., Lehman, C.L., Grisham, J.R., \& Mancill, R.B. (2001). Current and lifetime comorbidity of the DSM-IVanxiety and mood disorders in a large clinical sample. Journal of Abnormal Psychology, 110, 585-599.

Chelminski, I., \& Zimmerman, M. (2003). Pathological worry in depressed and anxious patients. Journal of Anxiety Disorders, 17, 533-546.

Contrada, R.J, Wright, R.A., \& Glass, D.C. (1984). Task difficulty, type A behavior pattern, and cardiovascular response. Psychophysiology, 21, 638-656.

Davey, G.C.L. (1993). A comparison of three cognitive appraisal strategies: The role of threat in devaluation of problem-focused coping. Personality and Individual Differences, 14, 535546.

Dua, J.K., \& King, D.A. (1987). Heart rate and skin conductance as measures of worrying. Behaviour Change, 4, 26-32.

Emmons, R.A., \& King, L.A. (1988). Implications for psychological and physical well being. Journal of Personality and Social Psychology, 54, 1040-1048.

Foa, E.B., \& Meadows, E.A. (1997). Psychosocial Treatments of Posttraumatic Stress Disorder: A Critical Review. Annual Review of Psychology, 48, 449-480.

Friedman, B.H., \& Thayer, J.F. (1998). Anxiety and autonomic flexibility: a cardiovascular approach. Biological Psychology, 49, 303-323.

Friedman, B.H., Thayer, J.F., Borkovec, T.D., Tyrrell, R.A., Johnsen, B.H., \& Colombo, R. (1993). Autonomic characteristics of nonclinical panic and blood phobia. Biological Psychiatry, 34, 298-310.

Frijda, N.H. (1988). The laws of emotion. American Psychologist, 43, 349-58.

Glynn, L.M., Christenfeld, N., \& Gerin, W. (2002). The role of rumination in recovery from reactivity: cardiovascular consequences of emotional states. Psychosomatic Medicine, 64, $714-726$.

Hazlett, R.L., \& Haynes, S.N. (1992). Fibromyalgia: A time-series Analysis of the Stress or Physical Symptom Association. Journal of Behavioural Medicine, 15, 541-558.

Ironson, G., Taylor, C.B., Boltwood, M., Bartzokis, T., Dennis, C., Chesney, M., Spitzer, S., \& Segall, G.M. (1992). Effects of anger on left ventricular ejection fraction in coronary artery disease. American Journal of Cardiology, 70, 281-5. 
Jadad, A.R., Moore, A.R., Carroll, D., Jekinson, C., Reynolds, D.J.M., Cavaghan, D.J., \& McQuay, H.J. (1996). Assessing the Quality of Reports of Randomized Clinical Trials: Is Blinding Necessary? Controlled Clinical Trials, 17, 1-12.

Kawachi, I., Colditz, G.A., Ascherio, A., Rimm, E.B., Giovannucci, E., Stampfer, M.J., \& Willett, W.C. (1994). Prospective study of phobic anxiety and risk of coronary heart disease in men. Circulation, 89, 1992-1997.

Kessler, R.C., McGonagle, K.A., Zhao, S., Nelson, C.B., Hughes, M., Eshleman, S.,Wittchen, H.-U.,\&Kendler, K.S. (1994). Lifetime and 12-month prevalence of DSM-III-R psychiatric disorders in the National Comorbidity Survey. Archives of General Psychiatry, 51, 8-19.

Kessler, R.C., Sonnega, A., Bromet, E., Hughes, M., \& Nelson, C. (1995). Posttraumatic stress disorder in the National Comorbidity Survey. Archives of General Psychiatry, 52, 10481060.

Kessler, R.C., Stang, P.E., Wittchen, H.-U., Ustun, T.B., Roy-Burne, P.P., \& Walters, E.E. (1998). Lifetime panicdepression comorbidity in the National Comorbidity Survey. Archives of General Psychiatry, 55, 801-808.

Kubzansky, L.D., Kawachi, I., Spiro, A.,Weiss, S.T., Vokonas, P.S., \& Sparrow D. (1997). Is worrying bad for your heart? A prospective study of worry and coronary heart disease in the normative aging study. Circulation, 95, 818-824.

Lampert, R., Jain, D., Burg, M.M., Batsford, W.P., \& McPherson, C.A. (2000). Destabilizing effects of mental stress on ventricular arrhythmias in patients with implantable cardioverter-defibrillators. Circulation, 101, 158-64.

Lane, P. (2008). Handling drop-out in longitudinal clinical trials: A comparison of the LOCF and MMRM approaches. Pharmaceutical Statistics, 7, 93-106.

Lok, C.F., \& Bishop, G.D. (1999). Emotion control, stress, and health. Psychology and Health, $14,813-27$.

Lovallo, W. R. (2004). Stress and health: biological and psychological interactions. 2nd ed. Thousand Oaks, California: Sage Publications.

Lyonfields, J.D., Borkovec, T.D., \& Thayer, J.F. (1995). Vagal tone in generalized anxiety disorder and the effects of aversive imagery and worrisome thinking. Behaviour Therapy, $26,457-466$. 
Lyubomirsky, S., Caldwell, N. D., \& Nolen-Hoeksema, S. (1998). Effects of Ruminative and Distracting Responses to Depressed Mood on Retrieval of Autobiographical Memories. Journal of Personality and Social Psychology, 75, 166-177.

Lyubomirsky, S., Kasri, F., \& Zehm, K. (2003). Dysphoric Rumination Impairs Concentration on Academic Tasks. Cognitive Therapy and Research, 27, 309-330.

Martin, L. L., \& Tesser, A. (1996). Some Ruminative Thoughts. In R. S. Wyer, Jr. (Ed.), Advances in Social Cognition (Vol. IX, pp. 1-47). Hillsdale, NJ: Lawrence Erlbaum Associates, Inc.

McLaughlin, K.A., Borkovec, T.D., \& Sibrava, N.J. (2007). The effects of worry and rumination on affect states and cognitive activity, Behavior Therapy, 38, 23-38.

Melamed, S. (1987). Emotional reactivity and elevated blood pressure. Psychosomatic Medicine, 49, 217-225.

Melamed, S. (1994). Life stress, emotional reactivity and their relation to plasma lipids in employed women. Stress \& Health, 1994, 167-175.

Melamed, S. (1996). Emotional reactivity, defensiveness, and ambulatory cardiovascular response at work. Psychosomatic Medicine, 58, 500-507.

Mellings, T.M., \& Alden, L.E. (2000). Cognitive Processes in Social Anxiety: The Effects of Self-focus, Rumination and Anticipatory Processing. Behaviour Research and Therapy, $38,243-257$.

Meyer, T.J., Miller, M.L., Metzger, R.L., Borkovec, T.D. (1990). Development and validation of the Penn State Worry Questionnaire. Behavior Research and Therapy, 28, 487-495.

Moher, D., Schulz, K.F., \& Altman, D.G. (2001). CONSORT GROUP (Consolidated Standards of Reporting Trials). The CONSORT statement: Revised recommendations for improving the quality of reports of parallel-group randomized trials. Annals of Internal Medicine, $134,657-62$.

Morrow, J.,\& Nolen-Hoeksema, S. (1990). Effects of responses to depression on the remediation of depressive affect. Journal of Personality and Social Psychology, 58, 519-527.

Nolen-Hoeksema, S. (2000). The role of rumination in depressive disorders and mixed anxiety/depressive symptoms. Journal of Abnormal Psychology, 109, 504-511.

Nolen-Hoeksema, S. (1991). Responses to depression and their effects on the duration of depressive episodes. Journal of Abnormal Psychology, 100, 569-582. 
Nolen-Hoeksema, S., \& Morrow, J. (1993). Effects of rumination and distraction on naturally occurring depressed mood. Cognition and Emotion, 7, 561-570.

Nolen-Hoeksema, S., \& Morrow, J. (1991). A prospective study of depression and posttraumatic stress symptoms after a natural disaster: the 1989 Loma Preita earthquake. Journal of Personality and Social Psychology, 61, 115e121.

Nolen-Hoeksema, S., Morrow, J., \& Fredrickson, B.L. (1993). Response styles and the duration of episodes of depressed mood. Journal of Abnormal Psychology, 102, 20-28.

Palatini, P., \& Julius, S. (1997). Heart rate and the cardiovascular risk. Journal of Hypertension, $15,3-17$.

Papageorgiou, C., \& Siegle, G.J. (2003). Rumination and depression: advances in theory and research. Cognitive Therapy and Research, 27, 243-245.

Petticrew, M., \& Gilbody, S. (2004). Planning and Conducting Systematic Reviews. In S. Michie, \& C. Abraham. (Eds.) Health Psychology in Practice. Oxford: BPS Blackwell Publishers.

Petticrew, M., \& Roberts, H. (2006). Systematic Reviews in the Social Sciences: A Practical Guide. Oxford: Blackwell Publishing.

Querstret, D., \& Cropley, M. (2012). Exploring the relationship between work-related rumination, sleep quality, and work-related fatigue. Journal of Occupational Health Psychology, 17, 341-353.

Raes, F., Hermans, D., \& Eelen, P. (2003). The Dutch version of the Ruminative Response Scale (RRS-NL) and the Rumination on Sadness Scale (RSS-NL). Gedragstherapie, 36, 97104.

Roger, D., \& Jamieson, J. (1988). Individual differences in delayed heart-rate recovery following stress: the role of extraversion, neuroticism and emotional control. Personality and Individual Differences, 9, 721-726.

Sarason, I.G., Pierce, G.R., \& Sarason, B.R. (Eds.). (1996). Cognitive interference: Theories, Methods, and Findings. Hillsdale, NJ: Erlbaum, Inc.

Schlotz, W., Hellhammer, J., Schulz, P., \& Stone A. (2004). Perceived work overload and chronic worrying predict weekend-weekday: Differences in the cortisol awakening response. Psychosomatic Medicine, 66, 207-214. 
Schwartz, A.R., Gerin, W., Davidson, K.D., Pickering, T.G., Brosschot, J.F., Thayer, J.F., Christenfeld, N., \& Linden, W. (2003). In search of a coherent model of stressor effects on short-term cardiovascular adjustments and the development of cardiovascular disease. Psychosomatic Medicine, 65, 22-35.

Segerstrom, S.C., Glover, D.A., Craske, M.G., \& Fahey, J.L. (1999). Worry affects the immune responses to phobic fear. Brain, Behavior, and Immunity, 13, 80-92.

Segerstrom, S.C., Solomon, G.F., Kemeny, M.E., \& Fahey, J.L. (1998). Relationship of worry to immune sequelae of the Northridge earthquake. Journal of Behavioral Medicine, 21, $433-450$.

Segerstrom, S.C., Stanton, A.L., Alden, L.E., \& Shortridge, B.E. (2003). A multidimensional structure for repetitive thought: What's on your mind, and how, and how much? Journal of Personality and Social Psychology, 85, 909-921.

Segerstrom, S.C., Tsao, J.C.I., Alden, L.E., \& Craske, M.G. (2000). Worry and rumination: Concomitant and predictor of negative mood. Cognitive Therapy and Research, 24, 671688.

Shapiro, S. (2001). The revised CONSORT Statement: Honing the cutting edge of the randomized controlled trial. Canadian Medical Association Journal, 164, 1157-1158.

Stein, P.K., \& Kleiger, R.E. (1999). Insights from the study of heart rate variability. Annual Review of Medicine, 50, 249-261.

Streiner, D.L. (2002). The case of the missing data: Methods of dealing with dropouts and other research vagaries. Canadian Journal of Psychiatry, 47, 68-75.

Swift, J.K. \& Greenberg, R.P. (2012). Premature Discontinuation in Adult Psychotherapy: A Meta-Analysis. Journal of Consulting and Clinical Psychology, 80, 547-559.

Szabo, M., \& Lovibond, P.F. (2002). The cognitive content of naturally occurring worry episodes. Cognitive Therapy and Research, 26, 167-177.

Tellegen, A. (1985) Structures of mood and personality and their relevance to assessing anxiety, with an emphasis on self-report. In A.H. Tuma \& J.D. Maser (EDs.), Anxiety and the anxiety disorders (pp.681-706). Hillsdale, NJ: Erlbaum.

Thayer, J.F., \& Friedman, B,H. (2004). A neurovisceral integration model of health disparities in aging. In: Anderson, N.B. (Ed.) Health disparities in the elderly. Washington (DC): The National Academies Press, pp. 567-603. 
Thayer, J.F., Friedman, B.H., \& Borkovec, T.D. (1996). Autonomic characteristics of generalized anxiety disorder and worry. Biological Psychiatry, 39, 255-266.

Thomsen, D.K., Mehlsen, M.Y., Olesen, F., Hokland, M., Viidik, A., Avlund, K., \& Zachariae, R. (2004). Is there an association between rumination and selfreported self-reported physical health? A one-year follow-up in a young and an elderly sample. Journal of Behavioral Medicine, 27, 215-31.

Trapnell, P.D., \& Campbell, J.D. (1999). Private self-consciousness and the five-factor model of personality: Distinguishing rumination from reflection. Journal of Personality and Social Psychology, 76, 284-304.

van Doornen, L.J.P., \& van Blokland, R.W. (1992). The relationship between cardiovascular and catecholamine reactions to laboratory and real life stress. Psychophysiology, 29, 173-181.

Watkins, E., \& Teasdale, J.D. (2001). Rumination and overgeneral memory in depression: Effects of self-focus and analytic thinking. Journal of Abnormal Psychology, 110, 353-

Watson, D., Clark, A., \& Tellegen, A. (1988). Development and Validation of Brief Measures of Positive and Negative Affect: The PANAS Scales. Journal of Personality and Social Psychology, 54, 1063-1070.

Williams, J.M.G. (1996). Depression and the specificity of autobiographical memory. In D. C. Rubin (Ed.), Remembering our past: Studies in autobiographical memory, (pp. 244-267). Cambridge, UK: Cambridge University Press.

Wood, A.M., White, I.R., \& Thompson, S.G. (2004). Are missing outcome data adequately handled? A review of published randomized controlled trials in major medical journals. Clinical Trials, 1, 368-376.

Wulsin, L.R., Vaillant, G.E., \& Wells, V.E. (1999). A systematic review of the mortality of depression. Psychosomatic Medicine, 61, 6-17.

\section{Studies included in the review}

Andersson, G., Paxling, B., Roch-Norlund, P., Ostman, G., Norgren, A., Almlov, J., Georen, L., Breitholtz, E., Dahlin, M., Cuijpers, P., Carlbring, P., \& Silverberg, F. (2012). Internet-Based Psychodynamic versus Cognitive Behavioral Guided Self-Help for Generalized Anxiety Disorder: A Randomized Controlled Trial. Psychotherapy and Psychosomatics, 81, 344-355.

Campbell, T.S., Labelle, L.E., Bacon, S.L., Faris, P., \& Carlson, L.E. (2012). Impact of MindfulnessBased Stress Reduction (MBSR) on attention, rumination and resting blood pressure in women with cancer: A waitlist-controlled study. Journal of Behavioural Medicine, 35, 262-271. 
Ekkers, W., Korrelboom, K., Huijbrechts, I., Smits, N., Cuijpers, P., \& van der Gaag, M. (2011). Competitive Memory Training for treating depression and rumination in depressed older adults: A randomized controlled trial. Behavior Research and Therapy, 49, 588-596.

Feldman, G., Greeson, J., \& Senville, J. (2010). Differential effects of mindful breathing, progressive muscle relaxation, and loving-kindness meditation on decentering and negative reactions to repetitive thoughts. Behavior Research and Therapy, 48, 1002-1011.

Jain, S., Shapiro, S.L., Swanick, S., Roesch, S.C., Mills, P.J., Bell, I., \& Schwartz, G.E.R. (2007). A Randomized Controlled Trial of Mindfulness Meditation Versus Relaxation Training: Effects on Distress, Positive States of Mind, Rumination, and Distraction. Annals of Behavioural Medicine, $33,11-21$.

Leichsenring, F., Salzer, S., Jaeger, U., Kachele, H., Kreische, R., Leweke, F., Ruger, U., Winkelbach, C., \& Leibling, E. (2009). Short-Term Psychodynamic Psychotherapy and Cognitive-Behavioral Therapy in Generalized Anxiety Disorder: A Randomized, Controlled Trial. American Journal of Psychiatry, 166, 875-881.

Paxling, B., Almlov, J., Dahlin, M., Carlbring, P., Breitholtz, E., Eriksson, T., \& Andersson, G. (2011). Guided Internet-Delivered Cognitive Behavior Therapy for Generalized Anxiety Disorder: A Randomized Controlled Trial, Cognitive Behaviour Therapy, 40, 159-173.

Robins, C.J., Keng, S-L., Ekblad, A.G., \& Brantley, J.G. (2012). Effects of Mindfulness-Based Stress Reduction on Emotional Experience and Expression: A Randomized Controlled Trial. Journal of Clinical Psychology, 68, 117-131.

Robinson, E., Titov, N., Andrews, G., McIntyre, K., Schwencke, G., \& Solley, K. (2010). Internet Treatment for Generalized Anxiety Disorder: A Randomized Controlled Trial Comparing Clinician vs. Technician Assistance. PLoS ONE, 5, e10942. Doi:10.1371/journal.pone.0010942

Shapiro, S.L., Oman, D., Thoresen, C.E., Plante, T.G., \& Flinders, T. (2008). Cultivating Mindfulness: Effects on Well-Being. Journal of Clinical Psychology, 64, 840-862.

Steinmetz, S.E., Benight, C.C., Bishop, S.L., \& James, L.E. (2012). My Disaster Recovery: a pilot randomized controlled trial of an Internet intervention. Anxiety, Stress \& Coping: An International Journal, 25, 593-600.

Titov, N., Andrews, G., Johnston, L., Robinson, E., \& Spence, J. (2010). Transdiagnostic Internet treatment for anxiety disorders: A randomized controlled trial. Behaviour Research and Therapy, 48, 890-899.

van Aalderen, J.R., Donders, A.R.T., Giommi, F., Spinhoven, P., Barendregt, H.P., \& Speckens, A.E.M. (2012). The efficacy of mindfulness-based cognitive therapy in recurrent depressed patients with 
and without a current depressive episode: a randomized controlled trial. Psychological Medicine, 42, 989-1001. doi:10.1017/ S0033291711002054.

Vollestad, J., Sivertsen, B., \& Nielsen, G.H. (2011). Mindfulness-based stress reduction for patients with anxiety disorders: Evaluation in a randomized controlled trial. Behaviour Research and Therapy, 49, 281-288. doi: 10.1016/j.brat.2011.01.007

Watkins, E.R., Baeyens, C.B., \& Read, R. (2009). Concreteness Training Reduces Dysphoria: Proof-ofPrinciple for Repeated Cognitive Bias Modification in Depression. Journal of Abnormal Psychology, 118, 55-64.

Watkins, E.R., Mullan, E., Wingrove, J., Rimes, K., Steiner, H., Bathurst, N., Eastman, R., \& Scott, J. (2011). Rumination-focused cognitive-behavioural therapy for residual depression: phase II randomised controlled trial. British Journal of Psychiatry, 199, 317-322. doi:

10.1192/bjp.bp.110.090282.

Watkins, E.R., Taylor, R.S. Baeyens, B.C., Read, R., Pearson, K., \& Watson, L. (2012). Guided self-help concreteness training as an intervention for major depression in primary care: a Phase II randomized controlled trial. Psychological Medicine, 42, 1359-1371. doi:10.1017/S0033291711002480.

Westra, H.A., Arkowitz, H., \& Dozois, D.A.J. (2009). Adding a motivational interviewing pretreatment to cognitive behavioral therapy for generalized anxiety disorder: A preliminary randomized controlled trial. Journal of Anxiety Disorders, 23, 1106-1117.

Wolitzky-Taylor, K.B., \& Telch, M.J. (2010). Efficacy of self-administered treatments for pathological academic worry: A randomized controlled trial. Behaviour Research and Therapy, 48, 840-850. 